IZA DP No. 8512

The Evolution of Rotation Group Bias:

Will the Real Unemployment Rate Please Stand Up?

Alan Krueger

Alexandre Mas

Xiaotong Niu

September 2014 


\title{
The Evolution of Rotation Group Bias: Will the Real Unemployment Rate Please Stand Up?
}

\author{
Alan Krueger \\ Princeton University \\ and IZA \\ Alexandre Mas \\ Princeton University \\ and IZA \\ Xiaotong Niu \\ Congressional Budget Office
}

Discussion Paper No. 8512

September 2014

\author{
IZA \\ P.O. Box 7240 \\ 53072 Bonn \\ Germany \\ Phone: +49-228-3894-0 \\ Fax: +49-228-3894-180 \\ E-mail: iza@iza.org
}

Any opinions expressed here are those of the author(s) and not those of IZA. Research published in this series may include views on policy, but the institute itself takes no institutional policy positions. The IZA research network is committed to the IZA Guiding Principles of Research Integrity.

The Institute for the Study of Labor (IZA) in Bonn is a local and virtual international research center and a place of communication between science, politics and business. IZA is an independent nonprofit organization supported by Deutsche Post Foundation. The center is associated with the University of Bonn and offers a stimulating research environment through its international network, workshops and conferences, data service, project support, research visits and doctoral program. IZA engages in (i) original and internationally competitive research in all fields of labor economics, (ii) development of policy concepts, and (iii) dissemination of research results and concepts to the interested public.

IZA Discussion Papers often represent preliminary work and are circulated to encourage discussion. Citation of such a paper should account for its provisional character. A revised version may be available directly from the author. 


\section{ABSTRACT \\ The Evolution of Rotation Group Bias: Will the Real Unemployment Rate Please Stand Up?*}

This paper documents that rotation group bias - the tendency for labor force statistics to vary systematically by month in sample in labor force surveys - in the Current Population Survey (CPS) has worsened considerably over time. The estimated unemployment rate for earlier rotation groups has grown sharply relative to the unemployment rate for later rotation groups; both should be nationally representative samples. The rise in rotation group bias is driven by a growing tendency for respondents to report job search in earlier rotations relative to later rotations. We investigate explanations for the change in bias. We find that rotation group bias increased discretely after the 1994 CPS redesign and that rising nonresponse is likely a significant contributor. Survey nonresponse increased after the redesign, and subsequently trended upward, mirroring the time pattern of rotation group bias. Consistent with this explanation, there is only a small increase in rotation group bias for households that responded in all eight interviews. An analysis of rotation group bias in Canada and the U.K. reveal no rotation group bias in Canada and a modest and declining bias in the U.K. There is not a "Heisenberg Principle" of rotation group bias, whereby the bias is an inherent feature of repeated interviewing. We explore alternative weightings of the unemployment rate by rotation group and find that, despite the rise in rotation group bias, the official unemployment does no worse than these other measures in predicting alternative measures of economic slack or fitting key macroeconomic relationships.

JEL Classification: J01, J64

Keywords: unemployment rate, measurement

Corresponding author:

Alexandre Mas

Industrial Relations Section

Firestone Library

Princeton University

Princeton, NJ 08544

USA

E-mail: amas@princeton.edu

\footnotetext{
* We thank Ann Polivka and seminar participants at the Bureau of Labor Statistics, Princeton University, and NBER for helpful comments. StatCan provided helpful statistical tabulations. This paper has not been subject to CBO's regular review and editing process. The views expressed here should not be interpreted as CBO's. The authors are responsible for all views expressed in the paper and any errors.
} 


\section{INTRODUCTION}

Many countries' labor force surveys have rotating panel structures to improve the precision of estimated changes in labor force statistics. In these surveys, households selected into the sample are interviewed several times. In the Current Population Survey (CPS), for example, households residing at an address selected into the sample are interviewed for four consecutive months, not interviewed for the next eight months, and then interviewed for an additional four months. In any given month, there are eight rotation groups in the sample, depending on the month in which their dwelling was first selected into the sample. Each rotation group should form a representative sample of the population, with the same labor force characteristics, apart from sampling errors. This is not the case, however. In the first half of 2014 , for example, the unemployment rate for the first and last rotation groups in the CPS were 7.5 percent and 6.1 percent, respectively. The official BLS unemployment rate for this period was 6.5 percent. $^{1}$ These differences raise the obvious question: What was the unemployment rate in the first half of 2014? Why does the unemployment rate vary across rotation groups?

A systematic tendency for differences in estimates across rotation groups is referred to as "rotation group bias". Bailar (1975) was among the first to document the rotation group bias in the CPS. Using data from 1968-1972, she found that the unemployment rate estimated from different rotation groups in the same time period were systematically different. She found that these differences came from the margin of out of the labor force rather than employment. Further, she documented something of a tilted W-shaped pattern, with the first and fifth rotation groups having the highest unemployment rates and slight upticks in the fourth and eighth rotation groups. There have been a number of papers aimed at understanding the implications of rotation

\footnotetext{
${ }^{1}$ These estimates are not seasonally adjusted. All of our analyses of the CPS weigh observations using the final weights.
} 
The Evolution of Rotation Group Bias

group bias on labor force statistics, but the magnitude and evolution of rotation group bias in the CPS has not been documented since Bailar's (1975) study. In this paper we estimate the magnitude of rotation group bias in the CPS over the period 1976-2014. We find that the magnitude and shape of this bias have evolved and grown over time. For example, between 2009 and 2013, the average unemployment rate in the CPS was 9.3 percent for respondents in the first rotation group, and 8.3 percent for respondents in the eighth rotation group. Between 1976 and 1980 the corresponding rates were 7.3 percent and 6.8 percent, respectively. Moreover, the pattern across rotation groups has become more continuously downward sloping rather than Wshaped.

Figure 1A shows the annual average unemployment rate for each rotation group, and Figure 1B shows the same results subtracting BLS's official unemployment rate from each measure. It is clear that there is a secular trend, with the unemployment rate calculated for households in their first interview (first rotation group) rising relative to the official measure, and the unemployment rate calculated for households in their final interview (eighth rotation group) falling relative to the official rate. These differential secular patterns are a vivid motivation for trying to understand the source of the evolving pattern of rotation group bias in the CPS.

We explore a number of possible explanations for the change in rotation group bias. These include changing patterns of survey nonresponse, survey redesign effects, the use of proxy responses, economic conditions, imputation for item nonresponse, and changes in unemployment duration. The evidence that we have assembled suggests that both changes in nonresponse rates and a changed response pattern due to some feature(s) of the 1994 CPS redesign played an important role in the increase in rotation group bias. 
The Evolution of Rotation Group Bias

The changes in the 1994 redesign included implementing computer-assisted telephone interviewing more broadly, dependent interviewing, and changes in the phrasing and skip logic of some of the labor force questions. The redesign also coincided with a discrete rise in nonresponse rates. The magnitude of rotation group bias jumped after 1993 and then increased thereafter faster than the preexisting trend. The redesign could have changed the pattern of rotation group bias through at least two channels: (i) increased survey nonresponse, which changed the composition of respondents across months in sample, and (ii) a changed response pattern due to the introduction of dependent interviewing and a new questionnaire and interview format. We find evidence supporting both channels.

Rotation group bias is related to survey nonresponse across demographic groups in crosssectional data. This relationship also holds when looking at changes over time. Relating the rate of survey nonresponse to a simple measure of rotation group bias each year shows that up to 45 percent of the jump in rotation group bias after 1993 can be accounted for by higher nonresponse rates.

Using the panel structure of the CPS we find a mild increase in rotation group bias for the subset of respondents who responded to the survey in all eight months. This finding suggests that a feature of the redesign changed the pattern of response, independent of any effect of the redesign on response rates. In particular, we find evidence suggesting that the redesign influenced the pattern of responses to the job search activity questions differentially across the rotation groups. After the redesign, respondents who were interviewed several times became less likely to report actively looking for a job, even if they were on a new jobless spell. We find little role for other candidate explanations for the change in rotation group bias. 
We also examine labor force surveys in Canada and the U.K. for evidence of rotation group bias. We find no evidence of rotation group bias in the Canadian survey, and a much smaller pattern in the U.K. survey than in the CPS. An analysis of labor force estimates in the U.K. with and without carry-forward imputation for non-respondents (which the U.K.'s Office of National Statistics uses to impute missing data) shows some evidence that the rotation group pattern in the U.K. survey is related to nonresponse. These results suggest that repeated questioning does not automatically lead to the same rotation group patterns as observed in the CPS, and that features of survey design and response rates matter critically for the extent of rotation group bias.

Lastly, we explore whether the unemployment rates calculated for different rotation groups have varying ability to predict alternative measures of economic slack. Ex ante it is unclear which of the CPS rotation groups has less bias and therefore should receive more weight in labor force statistics. Although we cannot assess the most accurate measure of the unemployment rate, we can assess whether some rotation groups have greater efficacy than others when it comes to predicting alternative measures of economic slack or fitting key macroeconomic relationships. Our approach is to compare the strength of the relationship between the unemployment rate of the eight different rotation groups with total capacity utilization (TCU) and the Insured Unemployment Rate (IUR). Both of these measures are closely related to the unemployment rate. Based on this analysis, we find suggestive evidence that earlier rotation groups (in particular, rotation groups 1, 2, 3 and 5) are stronger predictors of movements in TCU and IUR. However, adjusting the unemployment to put more weight on these rotations does not lead to a significant difference relative to the official rate in a price 
The Evolution of Rotation Group Bias

Phillips Curve equation, wage Phillips Curve equation or GDP growth equation, nor does using the first principal component of the eight month-in-sample (MIS) unemployment rates.

\section{DATA}

The CPS is a monthly survey of the labor force in the U.S. About 60,000 households are interviewed for each survey. The CPS is a sample of physical addresses with eight panels in a 48-4 rotation scheme. In each monthly survey, there are eight groups of respondents identified by the MIS of their residences.

This study uses the CPS basic monthly surveys collected between January 1976 and May 2014. During the sample period, the CPS went through a major redesign in 1994. Prior to 1994 (the pre-redesign period), interviews in MIS1 and MIS5 were conducted in person. In other months, a majority of the interviews was conducted over the phone. The phone interviews were either conducted from interviewers' homes or from one of two centralized computer-assisted telephone interviewing (CATI) facilities. Most of the interviews were conducted with a paperbased questionnaire: only about $9 \%$ of the data were collected by CATI (Polivka and Miller 1998). After the redesign, the new questionnaire was designed solely for computer-assisted interviewing. Computer-assisted personal interviewing (CAPI), where the interviewer visits the household, is currently used in MIS1 and MIS5 unless a telephone interview is requested by the household, and CATI is used for other months unless the household does not give permission for a telephone interview (in which case, the interview is done in person by CAPI). Due to the redesign, an increasing number of interviews have been conducted by CATI. ${ }^{2}$ The shift to computer-assisted interviewing permits dependent interviewing, which uses information from a

\footnotetext{
2 In 2004, the fraction of interviews collected by CATI was about $80 \%$ in months other than MIS1 and MIS5 (U.S. Department of Labor 2006).
} 
previous interview (often combined with answers to other questions) to update information for the current interview. This design feature is meant to reduce respondent burden. ${ }^{3}$

Additional details on sample construction are available in Appendix B.

\section{The Evolution of Rotation Group Bias In THE CPS}

Following Solon (1986), we focus on a multiplicative model to estimate rotation group bias. ${ }^{4}$ The multiplicative index for a rotation group in a given time period is computed by dividing the estimate for that rotation group by the average estimate over all eight rotation groups in the relevant time period and multiplying by 100. If there is no rotation group bias, the multiplicative index should be 100 for all rotation groups.

Figure 2 presents this index of the unemployment rate by MIS and year. As a handy summary measure of the degree of rotation group bias, each year we fit a linear slope through the rotation group indices (i.e., regress the multiplicative indices on a variable running from 1 to 8 representing the rotation group). The slope of the fitted line is presented next to the figure. In all years from 1976 to 2014, the slope is negative, implying that the estimated unemployment rates generally decrease with MIS.

We use the slope of the fitted line through the rotation groups as an approximate measure of the magnitude of rotation group bias. Figure 3 plots these slopes by year. The magnitude of

\footnotetext{
${ }^{3}$ Polivka and Miller (1998) study the effect of the redesign on different estimates of labor force statistics. Based on the results from the Parallel Survey, the authors calculated the multiplicative and additive factors for adjusting estimates after January 1994 to be consistent with estimates before January 1994. For example, the multiplicative factor for unemployment rate is about 1.009 , or the redesign increases the unemployment rate by about $1 \%$, though the change is not statistically significant.

${ }^{4}$ Bailar (1975) argued that the estimates of month-to-month changes are unbiased if the rotation group effects are constant over time and the effects are additive. Solon (1986) showed that the estimates of changes would be biased if the rotation group effects are multiplicative. Solon also provides empirical evidence that rejects the assumption of additive rotation group effects.
} 
the bias measure can be interpreted as the percentage change in the labor force statistic from an incremental interview month. For example, in 1994 the bias measure has a value of approximately -1 . This implies that, on average, every incremental month in rotation group was associated with a decline in the measured unemployment rate by one percent. (Note that the rotation groups are balanced each year: each year there are 12 observations on individuals in their first rotation group, 12 observations on individuals in their second rotation, etc. Thus, seasonality does not play a role in explaining the pattern of rotation group bias.)

Figure 3 shows that the magnitude of the bias for the unemployment rate increased over time, and almost doubled in absolute value following the 1994 CPS redesign. To assess significance of this increase, we fit the slope measure of bias to a linear time trend, a post-1993 dummy (solid line) and, in a second specification, their interaction (dashed line). These regressions are shown in the first two columns of Table 1 and the fitted values are displayed in Figure $3 .^{5}$ The results show clear statistical evidence of a level shift, with the post-1993 dummy statistically significant in both specifications. The time-post-93 interaction indicates that the magnitude of rotation group bias also gradually increased over time after 1993.

The shape of the rotation group pattern with respect to MIS also evolved over time. Table 2 presents the average multiplicative index for the unemployment rate from 1976 to 1993 , and surveys from 1994 to May 2014. Before the 1994 redesign, the index of unemployment rate exhibits a mildly tilted "W" shape: it decreases after MIS1 and MIS5, with upticks in MIS4 and

\footnotetext{
5 Formally, this can be viewed as a method of moments approach. An alternative approach for estimating rotation group bias is to construct a sample with year-by-MIS cells and regress the log of the unemployment rate in the cell on a MIS linear trend, the interaction of month in sample trend with a post-1993 indicator, and year dummies. Fitting this model we estimate a MIS coefficient $(\mathrm{x} 100)$ of $-0.9(\mathrm{t}-\mathrm{ratio}=-7.6)$ and an interaction between MIS and a post-1993 indicator variable $(\mathrm{x} 100)$ of $-1.0(\mathrm{t}-\mathrm{ratio}=-7.0)$.
} 
MIS8, consistent with Bailar's (1975) findings. ${ }^{6}$ Since 1994, the index of unemployment rate decreases monotonically with MIS with a small uptick in MIS5. The index for the number of unemployed workers shows a very similar pattern to that of the unemployment rate.

Table 2 also shows that the rotation group bias is smaller for the number of employed persons. $^{7}$ This finding suggests that rotation group bias in the unemployment rate is not driven by whether or not respondents are classified as being employed (see also the results for "not working last week" in Table 5 below). Instead, rotation group bias in unemployment results from the margin between being classified as unemployed or out of the labor force.

To summarize, two general trends in rotation group pattern of unemployment rate emerge. First, the unemployment rate decreased monotonically with MIS since 1994, while it exhibited a tilted "W" shape before 1994. Second, the magnitude of rotation group bias, as measured by the slope of the relationship between the multiplicative index of the unemployment rate and MIS, jumps up in 1994 and gradually increases from that higher level in subsequent years.

\section{CHANNELS}

We can broadly group the main sources of bias into two categories: nonresponse and redesign effects. In this section we focus on these candidate explanations. We begin by investigating the determinants of the cross-sectional pattern of interview effects, and then we examine the factors that shifted the pattern over time.

\footnotetext{
${ }^{6}$ Using the CPS basic monthly surveys from 1968 to 1972, Bailar (1975) finds that the index of unemployment rate starts to have a "W" shape after the 1970 redesign. Prior to 1970, the index for unemployment rate shows peaks in MIS1 and MIS5.

${ }^{7} \mathrm{We}$ have also examined the rotation group pattern using an additive index. The additive index for a rotation group in a given time period is the difference between the estimate for that rotation group and the average estimate over all rotation groups in that period. If there is no rotation group bias, the additive index should be 0 for all rotation groups. Figure A1 presents the additive index of unemployment rate for each rotation group by year. The rotation group pattern of additive index is similar to that of multiplicative index.
} 


\section{IV.1. Changes in the Magnitude and Pattern of Nonresponse}

We first consider survey nonresponse as a candidate mechanism for both the "baseline bias" (i.e., the fact that there was systematic rotation group effect before the launch of the redesigned CPS in 1994) and the change after 1993. For this analysis we consider "Type-A noninterviews," which represent households that are eligible for interviews but were not interviewed because of refusal, temporary absence, noncontact, and other non-interview reasons.

Figure 4 plots the rate of Type-A survey non-interview by year. There is a discrete upward jump in nonresponse by approximately two percentage points coinciding with the 1994 redesign. Subsequent to the redesign there is also a noticeable upward trend in nonresponse, with a dramatic acceleration occurring after 2009, driven by survey refusals. (The upturn in nonresponse beginning in 2010 coincided with publicity surrounding the 2010 Census, and calls by some irresponsible officials that individuals should not participate in the Census.) This pattern of nonresponse is similar to the time-series pattern of rotation group bias, which exhibits a break in 1994 and then a steeper downward trend over time. A scatter plot of the linear bias measure against Type-A nonresponse (see Figure 5) shows a strong relationship.

The relationship between nonresponse and rotation group bias also holds in crosssectional data from CPS if we disaggregate the data into race-by-age-by-sex cells. For this analysis, we pooled data from January 1994 to December 2011. We divide the sample into 20 groups based on gender (men and women), race (white and black), and age (16-24, 25-34, 35-44, 45-54, and 55-64). For each of the 20 groups the magnitude of rotation group bias and the rate of Type-A nonresponse were calculated. ${ }^{8}$

\footnotetext{
${ }^{8}$ The CPS does not report demographic information for members of non-interview households. To estimate the rate of Type-A non-interview for each of the 20 demographic groups, we can obtain demographic information for members of Type-A non-interview households from other surveys. For households classified as Type-A non-
} 
Table 3 presents the results from the regression analysis that examines the cross-sectional relationship between Type-A non-interview and rotation group bias. For all specifications, the dependent variable is the slope measure of the multiplicative rotation group bias of the unemployment rate. Column (1) presents the estimated coefficient on the rate of Type-A noninterview; Column (2) presents the estimated coefficient on the rate of refusal; and Column (3) presents the estimated coefficient on the rate of Type-A non-interview for reasons other than refusal. The relationship between the magnitude of rotation group bias and the rate of Type-A non-interview is statistically significant in all specifications. Type-A non-interview accounts for $30 \%$ of the cross-sectional variation in rotation group bias.

Column (3) of Table 1 formally tests whether nonresponse can account for the time-series pattern in rotation group bias. In column (1) we regress the bias measure from 1976-2014 against a time trend, and a post-1993 dummy. In column (3) we include the Type-A nonresponse rate. Without the nonresponse rate, the post-1993 dummy has a coefficient of -0.65 (t-ratio=2.25), and when we include the nonresponse rate the coefficient falls to -0.35 (t-ratio=-1.14). Thus, controlling for the nonresponse rate appears to account for almost half of the rise in rotation group bias after 1993, and renders the effect statistically insignificant. While we only have observational data and cannot conclude that increased nonresponse itself caused the change in the pattern of rotation group bias, it seems plausible that nonresponse or some factor related to nonresponse is responsible for a substantial share of the rise in rotation group bias.

interview in period $t$, we first try to obtain demographic information of their members from period $t-1$. If the information is unavailable in period $t-1$, we try to obtain the demographic information from period $t+1$. The rate of Type-A non-interview in period $t$ is the ratio of the number of persons residing in Type-A non-interview households of period $t$ and the sum of respondents in period $t$ and those residing in Type-A non-interview households of period $t$. For Type-A non-interview households of period $t$, the count is weighted by the weights in the period from which the demographic information is obtained. The rates of refusal and Type-A non-interview for reasons other than refusal are estimated in a similar way. For the regression analysis, MIS1 and MIS8 are excluded from the calculation of average rate. Figure A2 plots this cross-sectional relationship. 
The Evolution of Rotation Group Bias

\section{IV.2. Redesign Effects}

\section{Linked Sample}

To investigate the role of changes in reporting behavior we utilize the panel structure of the CPS. If changes in reporting behavior due to the redesign, as opposed to changes in the pattern of nonresponse, brought about the change in rotation group bias we would expect to see the shift in bias for respondents who participated in all eight interviews. We therefore link CPS panels from January 1976 to May 2014 to examine whether the rotation group pattern of unemployment holds for respondents who are present for all eight interviews. Details on the construction of the linked file are available in Appendix B.

We assemble a balanced panel of dwellings, which includes dwellings that are eligible for all eight interviews during the sample period (i.e., dwellings that were first selected into the sample between January 1976 and February 2013). ${ }^{9}$ To avoid mismatches, we keep matched interviews with consistent demographic characteristics, specifically the same reported gender, race, and age ( \pm 2 years) in all interviews. An individual is considered to be present in an interview if there is a valid entry for labor force status.

Table 4 presents multiplicative indices of the unemployment rate for the subset of individuals who are present in all eight interviews ("Present in MIS 1-8"), for respondents who report valid labor force status in at least one interview but not in all eight interviews ("Missing at least one”), and all respondents (“All”). We split the sample into periods 1982-93 and 19942014. (We start the sample in 1982 because information on Type-A nonresponse is only available consistently in the public-use files beginning in 1982.) It is notable that from 19821993 to 1994-2014 the magnitude of rotation group bias increased by less for those who

\footnotetext{
${ }^{9}$ We cannot construct a "balanced" panel of households. The specific household residing in a dwelling can change during the interview period.
} 
The Evolution of Rotation Group Bias

responded to the survey each month ( 0.25 points $)$ than for those who inconsistently participated in the sample ( 0.62 points). This finding suggests that a change in response behavior to the labor force questions, independent of any effect on nonresponse rates, played a secondary role in the change in rotation group bias compared with nonresponse. An important caveat, however, is that those respondents who are stable in terms of participating in the survey each month could be different in other respects and have a different response to the redesign than the less consistent survey participants.

\section{Components of unemployment}

We next explore how the response to labor force questions changed. We begin by decomposing the unemployment rate into several components. The BLS classifies a worker as unemployed if: 1) they are on layoff, are given a date to return to work, and are available for work; or 2) if they did not have a job in the last week, actively looked for a job in the last four weeks, and are currently available for work. Table 5 shows the rotation group pattern for these different components of the definition of unemployment. Specifically, we computed the fraction of respondents who stated they are on layoff, were not employed in the last week, looked for a job in the last four weeks, and are available for work. (The denominator for these rates is the number of people in the population. We then computed multiplicative indices, as with the unemployment rate.)

Consistent with the results in Table 2, we do not observe a change in the rotation group pattern on the employment margin: in the base 1976-1993 period there is no rotation group pattern in whether the respondent was working last week, nor do we find a change in the pattern from this period to 1976-1993. There is strong rotation group bias in the base period in the 
fraction of respondents who looked for work in the last week, and the linear measure of bias increases from 1.33 to 2.32 in absolute value. (Note that individuals are only asked about job search if they were without a job in the previous week.) We also observe an increase in bias for whether the respondent is available for work, with the magnitude of the linear bias measure rising from 1.21 to 2.34 in absolute value, but respondents are only asked about their availability for work if they in fact searched for a job. After the redesign, the CPS began asking respondents who reported looking for a job questions on the type of search in greater detail. There is a large degree of rotation group bias in the question of whether the worker used active job search methods. Rotation group bias also increases for the layoff question, but as can be seen in column (9), the share of respondents who report layoffs is quite low and declining and therefore unlikely to influence the overall pattern for the unemployment rate. Based on these results, it appears that the change in response behavior altered the margin for whether or not the respondent is classified to be in the labor force.

\section{3. Other explanations}

We have ruled out a number of additional explanations including changes in the redesign that changed how the labor force questions were worded for female respondents, changes in how people respond to labor force questions as a result of having been asked before, the use of imputation, proxy responses, economic conditions, and changes in unemployment duration.

\section{Changes by gender}

One possible feature of the redesign that could account for changes in labor force status is the change in how the labor force questions were worded for female respondents. In the 
unrevised CPS manual interviewers were instructed to assess whether the respondent "appears to be a homemaker," in which case the manual instructed the interviewer to ask "What were you doing most of last week -- keeping house or something else?" (Polivka and Miller 1998). The wording was changed so that there wouldn't be an asymmetry between men and women. This was one of several changes that potentially differentially affected the responses for men and women. Cohany, Polivka and Rothgeb (1994) found in the parallel CPS sample that these changes likely increased the unemployment rate of women relative to men.

We examine whether the change in rotation group bias could be due to the changes in question wording by gender by breaking out the index by gender and year. In Table 6 we show the multiplicative index for the unemployment rate for men and women, separately for 19761993 and 1994-2014. We see an increase in bias for both men and women, and it does not appear that the increase in bias is any larger for women. The index is very similar for men and women after 1994, but the magnitude of rotation group bias is greater for women before 1994. For men and women, the index exhibits the same "W" shape before 1994 and monotonic declining pattern since $1994 .^{10}$

\section{Changes in Responses due to Repeated Questioning}

It is possible that unemployed respondents who have already been interviewed are more likely to change their responses to the labor force question, for example if they want to minimize the length of the interview (now that they know the interview questions) or because they don't

\footnotetext{
${ }^{10}$ We have also looked at other characteristics. The magnitude of bias in unemployment rate is greater for the blacks. There is no consistent difference in the magnitude of bias across groups by age, ethnicity, urbanity or household size (results are not shown). The characteristics refer to the reported characteristics. Due to proxy responses, reported characteristics are different from the characteristics of respondents. On average, the magnitude of rotation group bias in unemployment rate is greater for self-responses compared to proxy responses.
} 
want to admit that they are still unemployed. We assess this explanation by comparing the magnitude of rotation group bias by different unemployment durations.

Figure 6 presents the multiplicative index for the fraction of the labor force unemployed by duration of unemployment and survey year. The figure shows that the change in rotation group bias occurred in the group that has been unemployed for less than four weeks. The estimated level shift in the slope measure of rotation group bias for this group is -2.34 (t-ratio=6.26). ${ }^{11}$ By contrast, around the time of the 1994 redesign, the magnitude of bias declines substantially for the fraction of unemployed workers who have been unemployed for 4-14 weeks. The estimated level shift is 0.61 (t-statistics=1.73). There is no statistically significant level shift for the fraction of unemployed workers with longer duration. ${ }^{12}$ The fact that rotation group bias has always been substantial for the newly unemployed and that this bias has increased is strong evidence that repeated questioning about job search activities of the unemployed is not the main driver of rotation group bias, as the bias is present during the first month of unemployment. This finding is also evidence against a related potential explanation, that by asking respondents about their labor force status the interviewers changed their behavior, making them less likely to search for a job.

\footnotetext{
${ }^{11}$ The estimation allows a linear time trend and a level shift between 1993 and 1994

${ }^{12} \mathrm{We}$ have also looked at the rotation group pattern by using different definitions of unemployment. The BLS publishes six unemployment rates that are either more or less inclusive than the official rate. Appendix Figure A3 presents the average multiplicative index by year for the official rate (U-3) as well as two less inclusive measures, U-1 and U-2, and three more inclusive measures, U-4, U-5 and U-6. U-1 corresponds to workers who are long-term unemployed, specifically the fraction of the labor force unemployed for 15 weeks longer, and U-2measures involuntary job separations or the fraction of workers in the labor force who lose jobs or complete temporary work. The increase in bias can be seen in U-2 and U-3, but not U-1. Because U-1 has a very different rotation group pattern since 1994, this is consistent with our finding that the increase in rotation group bias for U-3 is concentrated among workers with shorter unemployment spells. U-4, U-5, and U-6 were revised in the 1994 redesign. Since 1994, the indices for U-4, U-5, and U-6 show the same monotonically decreasing pattern with respect to MIS as the index for U3, though the magnitude of rotation group bias decreases from U-3 to U-6.
} 
Moreover, if we restrict the sample to workers who are newly unemployed using our longitudinal sample - i.e., they were either employed or out of the labor force in month $t$, but unemployed in month $\mathrm{t}+1$ - we find considerable rotation group bias for the newly unemployed. And the bias roughly doubled after the 1994 redesign. This finding implies that rotation group bias occurs even among those who were not asked about their job search behavior in the previous interview, because they were previously employed and therefore not asked the search questions. Thus, there is little support for a "Heisenberg Principle" of rotation group bias, in which repeated questioning about search activity inevitably alters subsequent responses.

Given the sharp increase in rotation group bias for the low duration group, it is also worth noting that much of the change in the duration pattern of unemployment across rotation groups is attributable to the introduction of dependent interviewing in the CPS redesign (Abraham and Shimer 2002). Since 1994, in months other than MIS1 and MIS5, if a worker reports being unemployed in the previous month and the current month, unemployment duration for the current month is automatically updated by adding either 4 or 5 weeks to the unemployment duration recorded in the previous month, depending on the number of weeks elapsed between the two interviews. The dependent interviewing for unemployment duration changes the composition of unemployed workers by duration; it should not affect reported labor force status or the unemployment rate. ${ }^{13}$ It is worth emphasizing that rotation group bias increased irrespective of duration. Thus, it is possible that the fact that rotation group bias has shifted primarily for short-term unemployed workers is largely an incidental result, owing to the

\footnotetext{
${ }^{13}$ There was also a change in the unit of reporting. In the redesigned questionnaire respondents were allowed to report duration in months or years in addition to weeks. Respondents were asked to report the duration in weeks if duration of four or fewer months were reported.
} 
The Evolution of Rotation Group Bias

adoption of dependent interviewing in rotation groups 2-4 and 6-8, not an independent source of the changing pattern of rotation group bias.

\section{Imputation for Item-Nonresponse}

Imputation is unlikely to be a factor since less than one percent of respondents have imputed labor force status. (Individuals who refuse to participate in the survey or do not respond for other reasons do not have their labor force status imputed; imputations are only done for those with incomplete responses.) The pattern of rotation group bias is very close when we remove imputed values (Table A1).

\section{Economic Conditions}

To test whether economic conditions affected the trend in bias we estimate the timeseries relationship between the bias measure and annual growth in GDP and unemployment rate (Table A2). Proportional changes in GDP and unemployment rate are not predictive of the bias.

\section{Proxy Response}

To save survey time, in the CPS one representative from each household answers questions for all other household members, or proxy-responses. Proxy-responses might be systematically different from self-responses and the fraction of proxy responses might change over MIS. Table A3 shows that self-responses exhibit greater rotation group bias in unemployment rate than proxy-responses. That difference between the two types of responses, however, has not changed over time. In addition, the share of proxy-responses does not vary across rotation groups. 


\section{Unemployment Duration}

Unemployment duration has trended upward over time (Valletta 1998, Aaronson, Mazumder, and Schechter 2010). Figure A4 shows the relationship between median annual unemployment duration and the measure of rotation group bias. There is a strong positive relationship, but it is entirely driven by the recession years 2009-2011. Without these observations there is no relationship. Thus, the rise in unemployment duration is unlikely to have played an important role in the increase in rotation group bias.

\section{EVIDENCE FROM THE U.K. AND CANADA}

Additional evidence supporting the role of nonresponse and the particulars of survey design in rotation group bias can be found by examining rotation group effects in the U.K. and Canadian labor force surveys (LFS).

\section{U.K. LFS}

The U.K. LFS has five rotation groups in its quarterly survey: each entering cohort is interviewed for 5 consecutive quarters and then out of the survey. ${ }^{14}$ Using data from quarterly surveys from 1993:Q4 to 2013:Q2, we find a very different rotation group pattern in the LFS

\footnotetext{
${ }^{14}$ In the CPS and the LFS of Canada, almost all individuals are interviewed during one week in the middle of each month, so the month of interview week and the month of reference week generally coincide. In the U.K. LFS, sampled households are divided into 13 groups and an interviewer contacts one group each week. For households interviewed at the beginning of a month/quarter, the month/quarter of the interview week will be different from the month/quarter of the reference week. For the discussion of the U.K. LFS, the calendar time refers to the time of interview.
} 
compared to the CPS. ${ }^{15}$ The top panel of Table 7 presents multiplicative indices for several labor force statistics. Population counts, as well as the numbers of employed and unemployed workers, decline with rotation group because the survey weights do not adjust for attrition (although missing values are imputed using the carry-forward method after the first interview). Unlike the count statistics, the unemployment rate is less sensitive to attrition, and there is only a modest pattern of rotation group bias for the unemployment rate, with a bias index (slope) of -0.79 , which is less than half of the magnitude in the CPS. Figure 7 plots the multiplicative indices of rotation group bias in unemployment rate by year. The pattern of bias varies across years but shows no obvious tendency of increasing.

In the U.K. LFS it appears that nonresponse plays a role in the observed rotation group pattern. The U.K. LFS has a significantly lower response rate than the CPS, and the response rate declines monotonically across rotation groups. For example, in the last quarter of 2010, the sample included around 15,000 eligible households in each rotation group; 63.5 percent of all eligible households responded in the first rotation group and 44.4 percent of all eligible households responded in the fifth rotation group (ONS 2011). In addition, the response rate has declined over time. For example, in September- November 1997, about 80 percent of all eligible households responded to the survey or had imputed values, compared to slightly more than 70 percent in the second quarter of 2006 (ONS 2009). Figure A5 plots the fraction of reported labor force participants with imputed labor force status from 1993 to 2013 . The rate of imputation increased from about 5 percent to almost 20 percent over the sample period.

\footnotetext{
${ }^{15}$ The U.K. LFS changed from an annual survey to a quarterly survey with rotating panel structure in the spring of 1992. The phase-in to quarterly survey was completed in the spring of 1993. Per the EU request, the U.K. LFS changed from seasonal quarters (winter, spring, summer, autumn) to calendar quarters in May 2006.
} 
The Evolution of Rotation Group Bias

Evidence that nonresponse plays a role in the U.K. rotation group pattern can be seen by looking at the rotation group pattern in the imputation rate. If a household does not provide responses after the first interview in the survey, responses from the previous quarter are used in the current quarter ("carry-forward imputation"). The rate is lower for later rotation groups because of the declining response rate across succeeding rotation groups. Including those imputed values, the response rates are comparable between rotation groups 1 and 2, and they start to decline for later rotation groups.

The carry-forward imputation method changes the bias pattern significantly for the counts by labor force status, but it has a small effect on the rotation group pattern of the unemployment rate itself. The bottom panel of Table 7 presents multiplicative indices of several labor force statistics without imputed labor force status. Because imputation starts with the second rotation group, we observe a sharper drop in the number of individuals between rotation groups 1 and 2 after removing imputed labor force status. As a result, the slope of multiplicative indices for the population declines from -4.85 to $-5.30 .^{16}$

The rotation group pattern by labor force status suggests that nonresponse is not random. The magnitude of rotation group bias in the unemployment rate is substantially greater if the imputed values are excluded. While the magnitude of bias increases for the number of employed and unemployed workers after removing imputed values, it declines for the number of individuals out of labor force. Imputation has a much greater effect on the magnitude of bias for counts by labor force status than the population counts. The slope of multiplicative indices

\footnotetext{
${ }^{16}$ Among unemployed workers, those with shorter unemployment duration have greater rotation group bias, but the imputation method has very little effect on the rotation group pattern (Table 7). The slope is -2.04 for the fraction of labor force participants with unemployment duration less than 3 months, and the slope is -2.48 for the same measure without imputed values.
} 
declined from -3.78 to -6.23 for the number of unemployed workers. These results imply that imputation changes the distribution of individuals by labor force status within each cohort.

\section{Canada's LFS}

The LFS of Canada is a monthly household survey. Since July 1995, about 54,000 households are included in the sample each month. There are six rotation groups, and each is interviewed for 6 consecutive months. Monthly surveys from January 1976 to December 2010 are used in our analysis. ${ }^{17}$ The nonresponse rate in the survey is relatively low, at just under 5 percent in 2005 (StatCan 2008). ${ }^{18}$

Table 8 presents multiplicative indices of several labor force statistics by rotation group from the Canadian LFS. The labor force statistics reported in the table are remarkably similar across rotation groups, and the rotation group bias is low throughout the sample period. There is no apparent tendency for the unemployment rate to decline across rotation groups; indeed, the slope measure is positive. The fraction of unemployed workers by duration of unemployment relative to the labor force is also very similar across rotation group. Figure 8 plots multiplicative indices of rotation group bias by year from 1976 to 2010. We do not observe any significant variation in rotation group pattern over time. ${ }^{19}$

To summarize, the international evidence suggests that rotation group bias in the measured unemployment rate in the U.K. is much weaker than that found in the CPS for the U.S.,

\footnotetext{
${ }^{17}$ The required data for this analysis are not publicly available. StatCan generously provided tabulations of the LFS by rotation group to us.

${ }^{18}$ If a non-responder was not interviewed in the previous month, a weight adjustment is made. Otherwise, all the labor force information is imputed using longitudinal hot-deck imputation. In addition to using information in the current period to define the imputation classes in hot-decking, longitudinal hot-deck imputation also uses information (responses or imputed values) from the previous period.

${ }^{19}$ Using an earlier sample from the Canadian LFS, Brisebois and Mantel (1996) find some evidence of rotation group effects.
} 
while there is no systematic tendency for rotation group bias in the Canadian LFS. Therefore, the magnitude of the rotation group pattern observed in the CPS is not a general phenomenon observed in all surveys with multiple interviews and a rotation group design. We also do not find an increase in rotation group bias in these other surveys, reinforcing our conclusion that the 1994 redesign played a significant role in the CPS. Lastly, we find evidence that in the U.K., the extent of rotation group bias is related to nonresponse, something we find evidence for as well in the CPS. These observations suggest that details of the surveys themselves, such as the nature of the questionnaire, mode of interviewing, and, relatedly, the survey response rate, play a pivotal role in shaping the extent and pattern of rotation group bias.

\section{Predicting Economic Slack ANd Other Macro Variables}

Figure 1 shows that the unemployment rates calculated for each of the rotation groups tend to move together, although over time there is an upward drift in the unemployment rate calculated for the lower rotation groups relative to that for the higher rotation groups. The official unemployment rate calculated by the BLS is a composite measure that places more weight on the continuing rotation groups, and less weight on rotation groups 1 and 5 . In analysis that we briefly summarize here, we explored whether it might be possible to combine the rotation groups in a more efficacious manner than the BLS's composite measure. The short answer is that the alternatives that we developed did not consistently do better than the official rate when it came to predicting key macroeconomic relationships.

In one set of analyses, to develop weights we first used the various rotation groups to predict alternative measures of economic slack, namely the capacity utilization rate and the insured unemployment rate. The results of this exercise are reported in Table 9. Although our 
estimates depended on whether we also included a linear time trend, this analysis showed some tendency for the unemployment rate in the earlier rotation groups $(1,2,3$ and 5) to be a stronger predictor of economic slack, and with the expected sign, than the later rotation groups. ${ }^{20}$ If we use the coefficients from the models in Table 9 to weight the unemployment rate by MIS and create an alternative measure of unemployment, however, the new measure does not perform significantly differently than the official BLS unemployment rate in a price Phillips Curve equation, wage Phillips Curve equation or GDP growth equation. ${ }^{21}$

Because the unemployment rates for each MIS tended to move together, in a second approach to reweighting the unemployment rate we estimated the first principal component of the eight MIS unemployment rates, and then used this measure together with the official BLS unemployment rate to estimate price and wage Phillips Curves and a GDP growth equation. Again, we did not find consistent evidence that the alternatively weighted unemployment rate performed differently than the official measure. Moreover, because the correlation between the first principal component of the MIS unemployment rates and the official rate was 0.9991, they are overwhelmingly measuring the same underlying factor. ${ }^{22}$ We conclude from this exercise that rotation group bias is probably not confounding the ability of the unemployment rate to predict key macroeconomic relationships in a meaningful way.

\footnotetext{
${ }^{20}$ The correlation between the average unemployment rate of MIS 1, 2, 3, 5 and the BLS official rate is 0.9981 , and the correlation between the average unemployment rate of MIS 4, 6, 7, 8 and the BLS official rate is 0.9989 . Thus, the high-frequency movements of the three measures are essentially identical.

${ }^{21}$ Specifically, we used annual data to relate the PCE (wage) inflation over year $t$ and both measures of the average unemployment rate over the months of year $t$ and lagged price inflation. We related GDP growth from Q4 to Q4 of year $t$ to the change in both measures of the unemployment rate over the same period.

${ }^{22}$ The weights assigned to each of the eight MIS unemployment rates in the first principal component are virtually identical: 0.12496, 0.12440, 0.12496, 0.12546, 0.12496, 0.12503, 0.12560, and 0.12468.
} 
The Evolution of Rotation Group Bias

\section{CONCLUSION}

In this paper we have documented that rotation group bias in the CPS has substantially worsened, with a marked increase in bias since the 1994 CPS redesign. We find suggestive evidence that the increase in rotation group bias is related to nonresponse, which follows a similar time-pattern as rotation group bias, as well as possible effects from the 1994 redesign of the CPS. The results suggest several important avenues for future research. While it does not appear that rotation group bias is severely confounding estimates of macroeconomic relationships, it remains an open question as to which rotation group provides the most accurate measure of the unemployment rate, and whether the increase in rotation group bias has affected the trend in the official unemployment rate. To assess these issues one would need an independent, unbiased unemployment measure, free of rotation effects, that when regressed on the MIS rates one would expect a coefficient of 1 , or a macroeconomic relationship between the unemployment rate and some other measure with a known coefficient. We leave this question to future work.

The results also suggest that there is not a "Heisenberg Principle" of rotation group bias, whereby rotation group bias is an inherent feature of any labor force survey with multiple interviews. This can be seen most clearly from the Canadian labor force survey that does not exhibit rotation group bias. This conclusion is also reinforced by the high degree of rotation group bias for those on new spells of unemployment, who have not previously been asked job search questions. These observations lead to the question of which aspects of survey design and implementation can be improved to mitigate rotation group bias. The evidence presented here suggests that we require a better understanding of survey nonresponse, particularly finding ways 
of reducing nonresponse and better imputation methods to adjust for nonrandom nonresponse, to help mitigate rotation group bias.

Lastly, we note that the potential for rotation group bias complicates the design and interpretation of overlap samples. For example, possible rotation group bias in the parallel sample that was surveyed to assess the effects of the 1994 redesign and rotation group bias in the CPS itself could confound the interpretation of differences between the two surveys as measuring the effect of the redesigned survey. 
The Evolution of Rotation Group Bias

\section{References}

Aaronson, Daniel, Bhashkar Mazumder, and Shani Schechter. "What is Behind the Rise in LongTerm Unemployment?." Economic Perspectives 34, no. 2 (2010).

Abraham, Katharine, and Robert Shimer. "Changes in unemployment duration and labor-force attachment," Alan Krueger, Robert Solow (Eds.), The Roaring Nineties, New York: The Russell Sage Foundation and Century Foundation (2002), pp. 367-420.

Bailar, Barbara A. "The Effects of Rotation Group Bias on Estimates from Panel Surveys." Journal of the American Statistical Association 70, no. 349 (1975): 23-30.

Brisebois, Francois, and Harold Mantel. "Month-in-sample effects for the Canadian Labour Force Survey." In Proceedings of the Survey Methods Section. 1996.

Cohany, Sharon R., Anne E. Polivka, and Jennifer M. Rothgeb. "Revisions in the current population survey effective January 1994." Emp. \& Earnings 41 (1994): 13.

Office for National Statistics (ONS) (2009) "Labour Force Survey user guide - volume 1: background and methodology 2009" http://doc.ukdataservice.ac.uk/doc/6632/mrdoc/pdf/lfs_user_guide voll background200 9.pdf.

(2011) "Labour Force Survey user guide - volume 1: background and methodology 2011" http://doc.ukdataservice.ac.uk/doc/7501/mrdoc/pdf/lfs_user_guide_vol1_background201 1.pdf.

Polivka, Anne E., and Stephen M. Miller. "The CPS after the redesign: Refocusing the economic lens." In Labor Statistics Measurement Issues, pp. 249-289. Chicago: University of Chicago Press, 1998.

Solon, Gary. "Effects of Rotation Group Bias on Estimation of Unemployment." Journal of Business \& Economic Statistics 4, no. 1 (1986): 105-109.

Statistics Canada (StatCan) (2008). "Methodology of the Canadian Labour Force Survey" http://www.statcan.gc.ca/pub/71-526-x/71-526-x2007001-eng.pdf.

U.S. Department of Labor, Bureau of Labor Statistics (2006). "Current Population Survey: design and methodology" http://www.census.gov/prod/2006pubs/tp-66.pdf.

Valletta, Robert G. "Changes in the Structure and Duration of US Unemployment, 1967-1998." Economic Review-Federal Reserve Bank of San Francisco (1998): 29-40. 
Table 1: Magnitude of Rotation Group Bias in Unemployment Rate and Type-A Non-interview over Time, 1976 - May 2014.

\begin{tabular}{|c|c|c|c|c|}
\hline & (1) & (2) & (3) & (4) \\
\hline Time & $\begin{array}{l}-0.021 \\
(0.013)\end{array}$ & $\begin{array}{c}0.012 \\
(0.020)\end{array}$ & $\begin{array}{c}0.008 \\
(0.018)\end{array}$ & $\begin{array}{c}0.015 \\
(0.020)\end{array}$ \\
\hline Post-93 & $\begin{array}{c}-0.649 * * \\
(0.288)\end{array}$ & $\begin{array}{c}-0.754 * * \\
(0.279)\end{array}$ & $\begin{array}{c}-0.350 \\
(0.306)\end{array}$ & $\begin{array}{l}-0.525 \\
(0.376)\end{array}$ \\
\hline Time*Post-93 & & $\begin{array}{c}-0.054 * * \\
(0.025)\end{array}$ & & $\begin{array}{l}-0.029 \\
(0.037)\end{array}$ \\
\hline Type A & & & $\begin{array}{c}-0.246^{* *} \\
(0.112)\end{array}$ & $\begin{array}{l}-0.149 \\
(0.164)\end{array}$ \\
\hline Constant & $\begin{array}{c}-1.007 * * * \\
(0.161)\end{array}$ & $\begin{array}{c}-0.695^{* * *} \\
(0.212)\end{array}$ & $\begin{array}{c}0.341 \\
(0.633)\end{array}$ & $\begin{array}{l}-0.016 \\
(0.775)\end{array}$ \\
\hline $\begin{array}{l}\mathrm{N} \\
\mathrm{R}^{2}\end{array}$ & $\begin{array}{c}39 \\
0.605\end{array}$ & $\begin{array}{c}39 \\
0.651\end{array}$ & $\begin{array}{c}39 \\
0.653\end{array}$ & $\begin{array}{c}39 \\
0.660\end{array}$ \\
\hline
\end{tabular}

Notes: The estimates are based on the CPS monthly files from January 1976 to May 2014. The unit of observation is calendar year. The dependent variable is the magnitude of rotation group bias in unemployment rate as described in the notes of Figure 2. "Time" is a linear time trend; "Post-93" is an indicator variable for years after 1993; "Time*Post-93" is the interaction of "Time" and "Post-93"; "Type A" is the number of type-A non-interview households divided by the sum of interviewed households and type-A non-interview households. 
The Evolution of Rotation Group Bias

Table 2: Multiplicative Indices of Rotation Group Bias in Labor Force Statistics, 1976 - May 2014.

\begin{tabular}{rrrrrrrrrrrr}
\hline & 1 & 2 & 3 & \multicolumn{1}{c}{4} & \multicolumn{1}{c}{5} & 6 & 7 & 8 & Mean & Slope & P-value \\
\hline 1976-1993 & & & & & & & & & & & \\
\# Unemp & 107.5 & 100.3 & 98.5 & 102.2 & 100.1 & 96.8 & 95.3 & 99.4 & 12,036 & -1.05 & 0.053 \\
\# Emp & 101.1 & 100.2 & 99.9 & 100.2 & 99.9 & 99.5 & 99.4 & 99.8 & 159,438 & -0.18 & 0.016 \\
Unemp Rate & 105.8 & 100.1 & 98.7 & 101.8 & 100.2 & 97.6 & 96.2 & 99.6 & $7.0 \%$ & -0.81 & 0.063 \\
& & & & & & & & & & & \\
1994-2014 & & & & & & & & & & & \\
\# Unemp & 110.8 & 105.1 & 101.2 & 98.9 & 99.7 & 95.9 & 94.0 & 94.4 & 13,051 & -2.21 & 0.000 \\
\# Emp & 101.0 & 100.5 & 100.4 & 100.1 & 99.8 & 99.3 & 99.4 & 99.6 & 200,340 & -0.23 & 0.001 \\
Unemp Rate & 109.2 & 104.3 & 100.9 & 98.9 & 100.0 & 96.8 & 94.9 & 95.1 & $6.1 \%$ & -1.86 & 0.000 \\
\hline
\end{tabular}

Notes: The estimates are based on the CPS monthly files from January 1976 to May 2014. The estimation of multiplicative indices is described in the notes of Figure 2. The table presents average annual estimates of three labor force statistics by MIS: the number of unemployed workers, the number of employed workers, and unemployment rate. The table also presents the average labor force statistics over eight rotation groups, the slope of those indices with respect to MIS, and p-value of the slope. The counts are in thousands. 
Table 3: Cross-sectional Relationship between the Rate of Type-A Non-interview and the Magnitude of Rotation Group Bias in Unemployment Rate, 1994 - 2011.

\begin{tabular}{lccc}
\hline & $(1)$ & $(2)$ & $(3)$ \\
\hline Type-A non-interview rate & $-0.4006^{* *}$ & & \\
Refusal rate & $(0.145)$ & $-0.9234^{* *}$ & \\
Other & & $(0.398)$ & $-0.6560^{* * *}$ \\
& & & $(0.223)$ \\
Constant & & & -0.2272 \\
& -0.1384 & -0.1795 & $(0.537)$ \\
$\mathrm{N}$ & $(0.601)$ & $(0.695)$ & 20 \\
$\mathrm{R}^{2}$ & & & 20 \\
\hline
\end{tabular}

Notes: The estimates are based on the linked CPS monthly files from January 1994 to December 2011. The sample is divided into 20 cells based on gender (men and women), race (white and black), and age group (16-24, 25-34, 3544, 45-54, and 55-64). For type-A non-interview households, demographic information is obtained from responses in the two adjacent rotation groups if available. The calculation of average rate of non-interview excludes respondents and type-A non-interview households in MIS1 and MIS8. The dependent variable is the magnitude of rotation group bias in unemployment rate as described in the notes of Figure 2. 
Table 4: Multiplicative Indices of Rotation Groups Bias in Unemployment Rate by Response Pattern Across Interviews, January 1982 - May 2014.

\begin{tabular}{|c|c|c|c|c|c|c|c|c|c|c|c|}
\hline & & 1 & 2 & 3 & 4 & 5 & 6 & 7 & 8 & Mean & Slope \\
\hline \multirow[t]{3}{*}{$82-93$} & Present in MIS 1-8 & 108.5 & 103.5 & 101.4 & 105.3 & 94.7 & 94.9 & 94.1 & 97.5 & $5.4 \%$ & -1.84 \\
\hline & Missing at least one & 108.9 & 100.8 & 99.2 & 102.7 & 100.6 & 96.9 & 93.9 & 96.9 & $9.2 \%$ & -1.52 \\
\hline & All & 108.1 & 102.0 & 100.2 & 103.7 & 98.1 & 96.3 & 94.2 & 97.3 & $6.9 \%$ & -1.57 \\
\hline \multirow[t]{3}{*}{$94-14$} & Present in MIS 1-8 & 109.5 & 105.8 & 101.8 & 100.1 & 97.3 & 95.4 & 94.4 & 95.7 & $5.0 \%$ & -2.09 \\
\hline & Missing at least one & 112.5 & 102.4 & 99.2 & 97.7 & 103.6 & 97.7 & 94.3 & 92.5 & $8.0 \%$ & -2.14 \\
\hline & All & 110.1 & 104.4 & 100.9 & 99.2 & 100.0 & 96.6 & 94.5 & 94.3 & $6.1 \%$ & -2.05 \\
\hline
\end{tabular}

Notes: The estimates are based on the linked CPS monthly files from January 1982 to May 2014. The estimation of multiplicative indices, mean, and slope is estimated as described in the notes of Figure 2. "Present in MIS 1-8" includes respondents who have valid labor force status for all eight interviews; "Missing at least one" includes those who are present in at least one interview, but do not provide valid labor force status in at least one of the eight interviews; "All" includes all respondents. The linked sample is restricted to include cohorts with matching rate greater than $40 \%$ and individuals with consistent age ( \pm 2 years), gender, and race in all interviews. 
Table 5: Multiplicative Indices of Rotation Groups Bias in the Fraction of the Population by Response to Unemployment Questions, 1976 - May 2014.

\begin{tabular}{|c|c|c|c|c|c|c|c|c|c|c|}
\hline & 1 & 2 & 3 & 4 & 5 & 6 & 7 & 8 & Mean & Slope \\
\hline \multicolumn{11}{|c|}{ Layoff } \\
\hline $76-93$ & 103.8 & 98.1 & 98.2 & 102.7 & 97.8 & 98.2 & 99.1 & 102.1 & $0.7 \%$ & -0.14 \\
\hline $94-14$ & 106.4 & 103.8 & 99.0 & 101.4 & 100.3 & 95.4 & 95.0 & 98.7 & $0.5 \%$ & -1.31 \\
\hline \multicolumn{11}{|c|}{ Not working last week } \\
\hline $76-93$ & 98.2 & 99.8 & 100.2 & 100.0 & 99.9 & 100.7 & 100.8 & 100.5 & $43.0 \%$ & 0.27 \\
\hline $94-14$ & 98.6 & 99.9 & 99.9 & 100.1 & 100.4 & 100.5 & 100.3 & 100.3 & $41.0 \%$ & 0.20 \\
\hline \multicolumn{11}{|c|}{ Looked for job in the last 4 weeks } \\
\hline $76-93$ & 109.0 & 100.7 & 98.3 & 101.7 & 101.2 & 96.5 & 94.2 & 98.5 & $4.3 \%$ & -1.33 \\
\hline $94-14$ & 111.6 & 105.0 & 101.4 & 98.5 & 99.2 & 96.4 & 94.3 & 93.5 & $3.9 \%$ & -2.32 \\
\hline \multicolumn{11}{|c|}{ Active job search methods } \\
\hline $76-93$ & - & - & - & - & - & - & - & - & - & - \\
\hline $94-14$ & 112.6 & 104.8 & 100.9 & 98.2 & 99.9 & 96.1 & 93.9 & 93.6 & $3.6 \%$ & -2.38 \\
\hline \multicolumn{11}{|c|}{ Available if offered a job last week } \\
\hline $76-93$ & 108.0 & 100.7 & 98.6 & 102.1 & 100.5 & 96.7 & 94.6 & 98.8 & $3.9 \%$ & -1.21 \\
\hline $94-14$ & 112.1 & 105.0 & 101.1 & 98.3 & 99.5 & 96.2 & 94.1 & 93.7 & $3.5 \%$ & -2.34 \\
\hline
\end{tabular}

Notes: The estimates are based on the CPS monthly files from January 1976 to May 2014. The estimation of multiplicative indices, mean, and slope is described in the notes of Figure 2. The table presents several statistics as fractions of the population: the number of workers who are laid off, the number of individuals not working last week, the number of individuals who looked for a job in the last 4 weeks among those who did not work last week, the number of active job seekers among those who looked for a job in the last 4 weeks, and the number of individuals who would be available for a job last week among job seekers. 
Table 6: Multiplicative Indices of Rotation Groups Bias in Unemployment Rate by Gender, 1976 - May 2014.

\begin{tabular}{|c|c|c|c|c|c|c|c|c|c|c|}
\hline & 1 & 2 & 3 & 4 & 5 & 6 & 7 & 8 & Mean & Slope \\
\hline 1976-1993 & & & & & & & & & & \\
\hline Men & 103.7 & 100.2 & 99.5 & 101.9 & 99.4 & 98.1 & 97.5 & 99.7 & $6.9 \%$ & -0.57 \\
\hline $\begin{array}{l}\text { Women } \\
\text { 1994-2014 }\end{array}$ & 108.3 & 100.0 & 97.7 & 101.8 & 101.2 & 96.9 & 94.6 & 99.5 & $7.3 \%$ & -1.09 \\
\hline Men & 109.1 & 104.0 & 100.9 & 98.9 & 100.0 & 97.0 & 94.9 & 95.1 & $6.3 \%$ & -1.84 \\
\hline Women & 109.3 & 104.6 & 100.7 & 98.9 & 99.9 & 96.6 & 94.9 & 95.1 & $5.9 \%$ & -1.89 \\
\hline
\end{tabular}

Notes: The estimates are based on the CPS monthly files from January 1976 to May 2014. The estimation of multiplicative indices, mean, and slope is described in the notes of Figure 2. 
Table 7: Multiplicative Indices of Rotation Group Bias in Labor Force Statistics (U.K. LFS), 1993Q4 - 2013Q2.

\begin{tabular}{|c|c|c|c|c|c|c|c|}
\hline & 1 & 2 & 3 & 4 & 5 & Average & Slope \\
\hline \multicolumn{8}{|c|}{ Full Sample } \\
\hline \# Employed & 103.2 & 106.5 & 100.9 & 96.4 & 93.1 & $5,582.3$ & -2.95 \\
\hline \# Unemployed & 102.7 & 109.1 & 102.0 & 95.7 & 90.5 & 393.3 & -3.78 \\
\hline \# NILF & 123.6 & 100.3 & 95.2 & 91.5 & 89.3 & $3,503.7$ & -8.00 \\
\hline Population $(16+)$ & 110.7 & 104.3 & 98.8 & 94.6 & 91.6 & $9,479.4$ & -4.85 \\
\hline Unemployment Rate & 99.7 & 102.4 & 101.1 & 99.4 & 97.5 & $6.6 \%$ & -0.79 \\
\hline Emp-Pop Ratio & 93.8 & 101.6 & 101.7 & 101.6 & 101.3 & $59.1 \%$ & 1.59 \\
\hline \multicolumn{8}{|c|}{ Unemployment Duration } \\
\hline$\%$ LF less than 3 months & 102.9 & 103.3 & 100.1 & 98.6 & 95.1 & $2.3 \%$ & -2.04 \\
\hline$\%$ LF 3-6 months & 94.5 & 104.1 & 104.1 & 99.5 & 97.8 & $1.1 \%$ & 0.19 \\
\hline$\%$ LF 6-12 months & 96.0 & 100.8 & 103.2 & 101.1 & 98.8 & $1.1 \%$ & 0.59 \\
\hline$\%$ LF $12-24$ months & 99.6 & 99.7 & 99.0 & 99.9 & 101.8 & $0.9 \%$ & 0.45 \\
\hline$\%$ LF 24 months or more & 102.1 & 101.8 & 99.6 & 98.8 & 97.8 & $1.1 \%$ & -1.15 \\
\hline
\end{tabular}

Full Sample Without Imputed Labor Force Status

\begin{tabular}{lrrrrrrr} 
\# Employed & 112.8 & 102.5 & 98.2 & 93.9 & 92.5 & $5,109.6$ & -4.85 \\
\# Unemployed & 114.8 & 104.5 & 98.4 & 92.8 & 89.5 & 351.4 & -6.23 \\
\# NILF & 118.2 & 101.6 & 96.7 & 92.5 & 91.1 & $2,086.0$ & -6.23 \\
Population (16+) & 114.4 & 102.4 & 97.8 & 93.5 & 92.0 & $7,546.9$ & -5.30 \\
Unemployment rate & 101.9 & 101.9 & 100.3 & 99.0 & 97.0 & $6.4 \%$ & -1.31 \\
Emp-Pop Ratio & 98.5 & 100.1 & 100.4 & 100.4 & 100.5 & $67.7 \%$ & 0.43 \\
\% LF less than 3 months & 104.9 & 102.8 & 99.1 & 98.5 & 94.6 & $2.3 \%$ & -2.48 \\
\% LF 3-6 months & 97.3 & 104.7 & 103.1 & 98.5 & 96.5 & $1.1 \%$ & -0.78 \\
\% LF 6-12 months & 98.8 & 100.4 & 102.5 & 100.3 & 98.0 & $1.1 \%$ & -0.18 \\
\% LF 12-24 months & 102.2 & 98.0 & 98.6 & 99.9 & 101.4 & $0.9 \%$ & 0.02 \\
\% LF 24 months or more & 103.6 & 100.5 & 98.5 & 99.0 & 98.5 & $1.1 \%$ & -1.18 \\
\hline
\end{tabular}

Notes: The estimates are based on the U.K. LFS from 1993Q4 to 2013Q2. The table presents multiplicative indices of several labor force statistics by rotation group (with and without imputed labor force status), the average value over rotation groups, and the slope of multiplicative indices. The estimation of multiplicative indices and slopes is presented in the notes of Figure 2. The set of labor force statistics includes the number of employed and unemployed workers, the number of individuals out of labor force, population, unemployment rate, and employment-population ratio. Among unemployed workers, the table presents the fraction of labor force by unemployment duration. The counts are in thousands. 
Table 8: Multiplicative Indices of Rotation Group Bias in Labor Force Statistics (Canadian LFS), $1976-2010$.

\begin{tabular}{|c|c|c|c|c|c|c|c|c|}
\hline & 1 & 2 & 3 & 4 & 5 & 6 & Average & Slope \\
\hline \# Employed & 99.9 & 99.9 & 100.0 & 100.3 & 100.2 & 99.7 & 26,770 & 0.00 \\
\hline \# Unemployed & 99.7 & 99.8 & 99.6 & 100.5 & 99.6 & 100.7 & 2,462 & 0.16 \\
\hline \# NILF & 100.3 & 100.2 & 100.0 & 99.4 & 99.8 & 100.4 & 15,175 & -0.03 \\
\hline \# Population & 100.0 & 100.0 & 100.0 & 100.0 & 100.0 & 100.0 & 44,408 & 0.00 \\
\hline Unemployment Rate & 99.8 & 99.9 & 99.6 & 100.2 & 99.5 & 101.0 & $8.5 \%$ & 0.15 \\
\hline Emp-Pop Ratio & 99.9 & 99.9 & 100.0 & 100.3 & 100.2 & 99.7 & $60.1 \%$ & 0.00 \\
\hline \multicolumn{9}{|c|}{ Unemployment Duration } \\
\hline$<5$ weeks & 99.7 & 98.7 & 100.1 & 100.3 & 100.0 & 101.3 & $2.6 \%$ & 0.35 \\
\hline 5-15 weeks & 100.2 & 100.1 & 98.8 & 99.8 & 99.5 & 101.6 & $2.5 \%$ & 0.19 \\
\hline $16-26$ weeks & 99.4 & 100.4 & 99.7 & 100.8 & 99.7 & 99.9 & $1.4 \%$ & 0.06 \\
\hline$>27$ weeks & 99.8 & 101.3 & 99.5 & 100.3 & 98.3 & 100.7 & $1.8 \%$ & -0.10 \\
\hline Missing & 98.6 & 100.8 & 99.4 & 100.8 & 101.6 & 98.8 & $0.3 \%$ & 0.14 \\
\hline
\end{tabular}

Notes: The estimates are based on the labor force statistics by rotation group and month provided by the Statistics Canada. The sample period goes from January 1976 to December 2010. The table presents several labor force statistics by rotation group, the average value over rotation groups, and the slope of multiplicative indices. The estimation of multiplicative indices and slopes is presented in the notes of Figure 2. The set of labor force statistics includes the number of employed and unemployed workers, the number of individuals out of labor force, population, unemployment rate, and employment-population ratio. Among unemployed workers, the table presents the fraction of labor force by unemployment duration. The counts are in thousands. 
Table 9: Relationship between Measures of Economic Slack (Total Capacity Utilization Rate and Insured Unemployment Rate) and the Unemployment Rate for Each Rotation Group, Multiple Regression Estimates with Monthly Data, 1976-2014.

\begin{tabular}{lcccc}
\hline & \multicolumn{2}{c}{ Log of 1 Minus TCUR } & \multicolumn{2}{c}{ Log of IUR } \\
\hline Log of Unemployment Rate & & & & \\
MIS 1 & $0.343^{* *}$ & 0.173 & 0.159 & $0.380^{* * *}$ \\
& $(0.142)$ & $(0.132)$ & $(0.140)$ & $(0.109)$ \\
MIS 2 & $0.775^{* * *}$ & $0.289^{* * *}$ & -0.269 & $0.365^{* * *}$ \\
& $(0.146)$ & $(0.107)$ & $(0.179)$ & $(0.110)$ \\
MIS 3 & $0.423^{* * *}$ & 0.170 & -0.0162 & $0.313^{* * *}$ \\
& $(0.152)$ & $(0.108)$ & $(0.121)$ & $(0.101)$ \\
MIS 4 & $-0.371^{* * *}$ & -0.120 & 0.111 & $-0.215^{*}$ \\
& $(0.113)$ & $(0.101)$ & $(0.128)$ & $(0.121)$ \\
MIS 5 & -0.0829 & 0.0272 & $0.398^{* * *}$ & $0.255^{* * *}$ \\
& $(0.120)$ & $(0.0933)$ & $(0.119)$ & $(0.0757)$ \\
MIS 6 & 0.0440 & 0.0274 & 0.121 & $0.142^{*}$ \\
& $(0.112)$ & $(0.0848)$ & $(0.100)$ & $(0.0822)$ \\
MIS 7 & -0.0480 & 0.0343 & 0.0800 & -0.0273 \\
& $(0.108)$ & $(0.0929)$ & $(0.109)$ & $(0.101)$ \\
MIS 8 & $-0.588^{* * *}$ & -0.102 & $0.355^{* *}$ & $-0.278^{* * *}$ \\
& $(0.155)$ & $(0.118)$ & $(0.179)$ & $(0.0844)$ \\
Linear time trend & & $0.000620^{* * *}$ & & $-0.000807^{* * *}$ \\
(monthly) & & $(0.000142)$ & & $(0.000151)$ \\
Constant & -0.305 & $-0.518^{* *}$ & $-1.019 * * *$ & $-0.741^{* * *}$ \\
& $(0.205)$ & $(0.221)$ & $(0.248)$ & $(0.177)$ \\
& & & & \\
Test joint significance (p-value) & 0.0000 & 0.0000 & 0.0000 & 0.0000 \\
Test equality (p-value) & 0.0000 & 0.3163 & 0.3654 & 0.0004 \\
N & & & & \\
R ${ }^{2}$ & 461 & 461 & 461 & 461 \\
& 0.448 & 0.583 & 0.731 & 0.833 \\
\hline
\end{tabular}

Notes: The estimates are based on the CPS monthly files from January 1976 to May 2014. The unit of observation is calendar month. The dependent variable is either the log of 1 minus TCU or the log of IUR. The set of explanatory variables includes a set of unemployment rates from eight rotation groups and a linear time trend. Each of the eight series of unemployment rate is seasonally adjusted using the X-12-ARIMA program from the Census. The table also presents p-values of two hypothesis tests: joint significances or equality of the coefficients on unemployment rates. The standards errors are Newey-West standard errors with a lag of 12 months. 
Figure 1: Unemployment Rate by Rotation Group and Year, 1976 - May 2014.

(A) Absolute Level

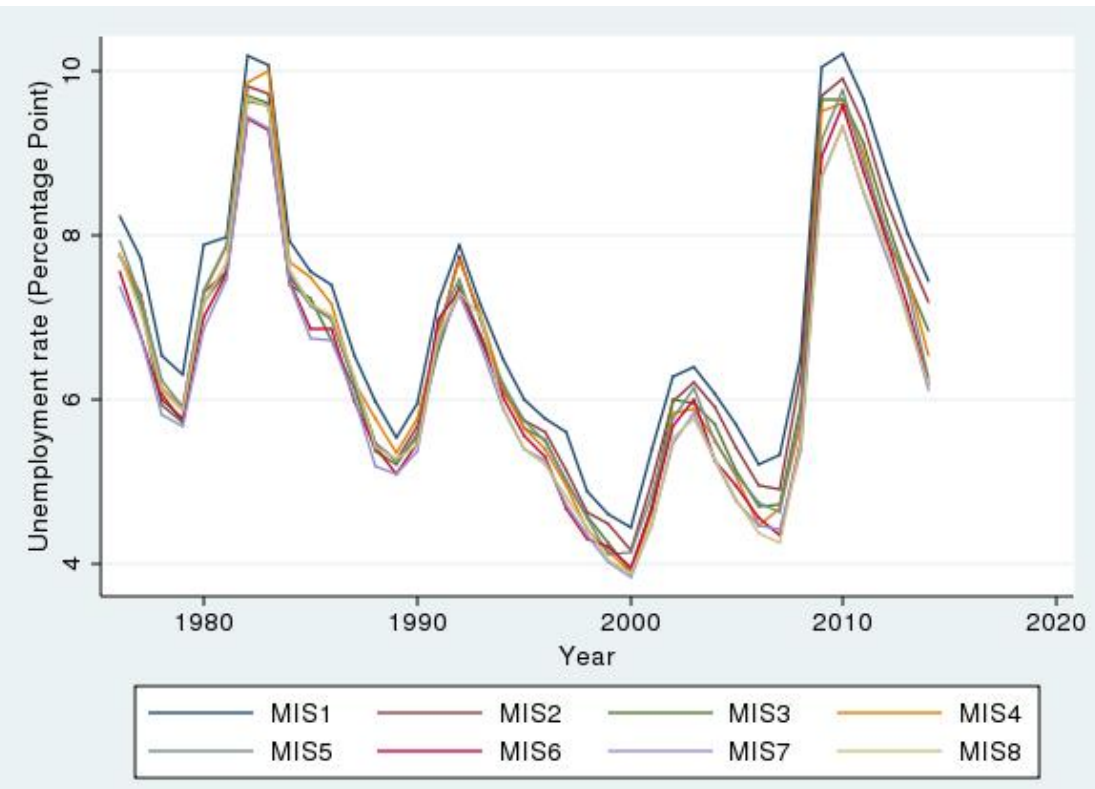

(B) Difference from the BLS Estimates

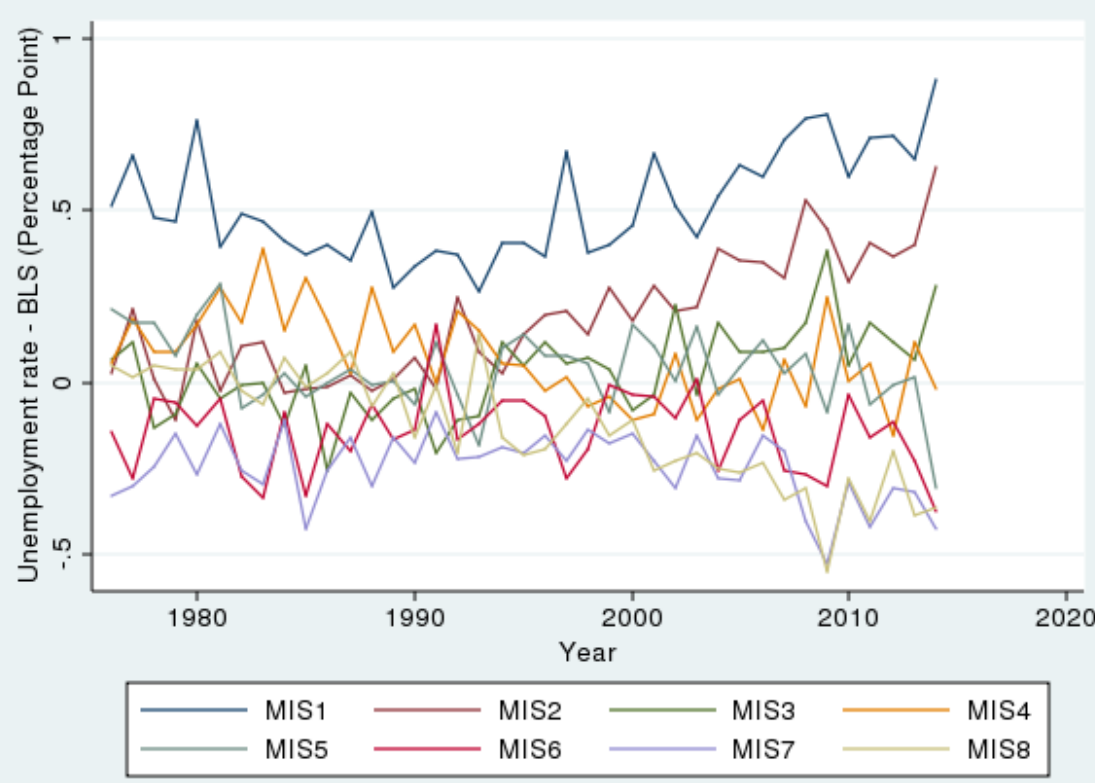

Notes: The estimates are based on the CPS monthly files from January 1976 to May 2014. Panel (A) plots unemployment rate by MIS and year; Panel (B) plots the difference between annual unemployment rate by MIS and the annual unemployment rate published by the BLS. 
Figure 2: Multiplicative Indices of Rotation Group Bias in Unemployment Rate, 1976 - May 2014.

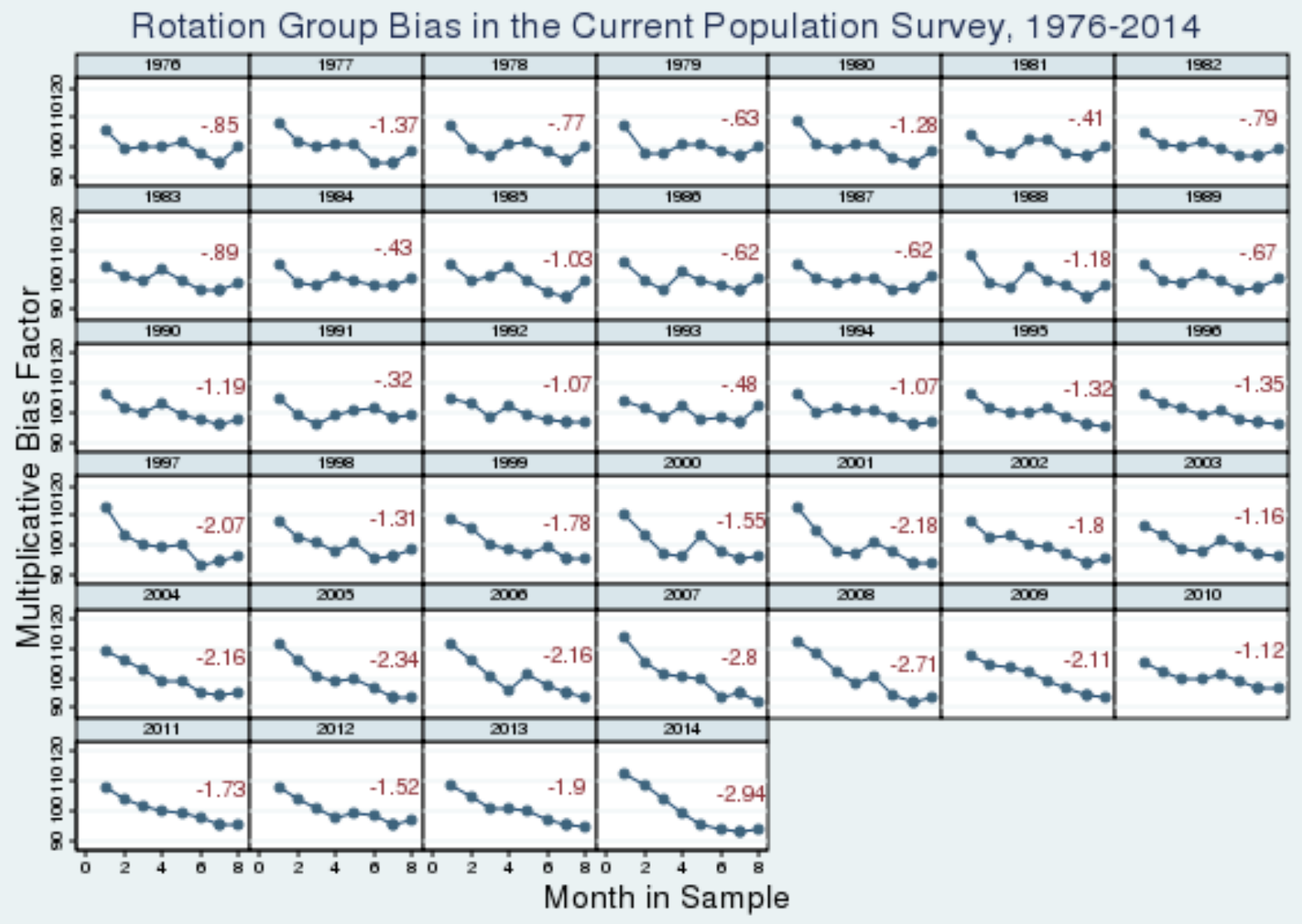

Notes: The estimates are based on the CPS monthly files from January 1976 to May 2014. The figure plots multiplicative indices by year, and the slope is presented next to the figure. The multiplicative index is estimated by dividing the estimate in a given rotation group by the average estimate over all eight rotation groups, and multiplying by 100 . The slope is the linear slope of multiplicative indices with respect to MIS. 


\section{The Evolution of Rotation Group Bias}

Figure 3: Magnitude of Rotation Group Bias in Unemployment Rate over Time, 1976 - May 2014.

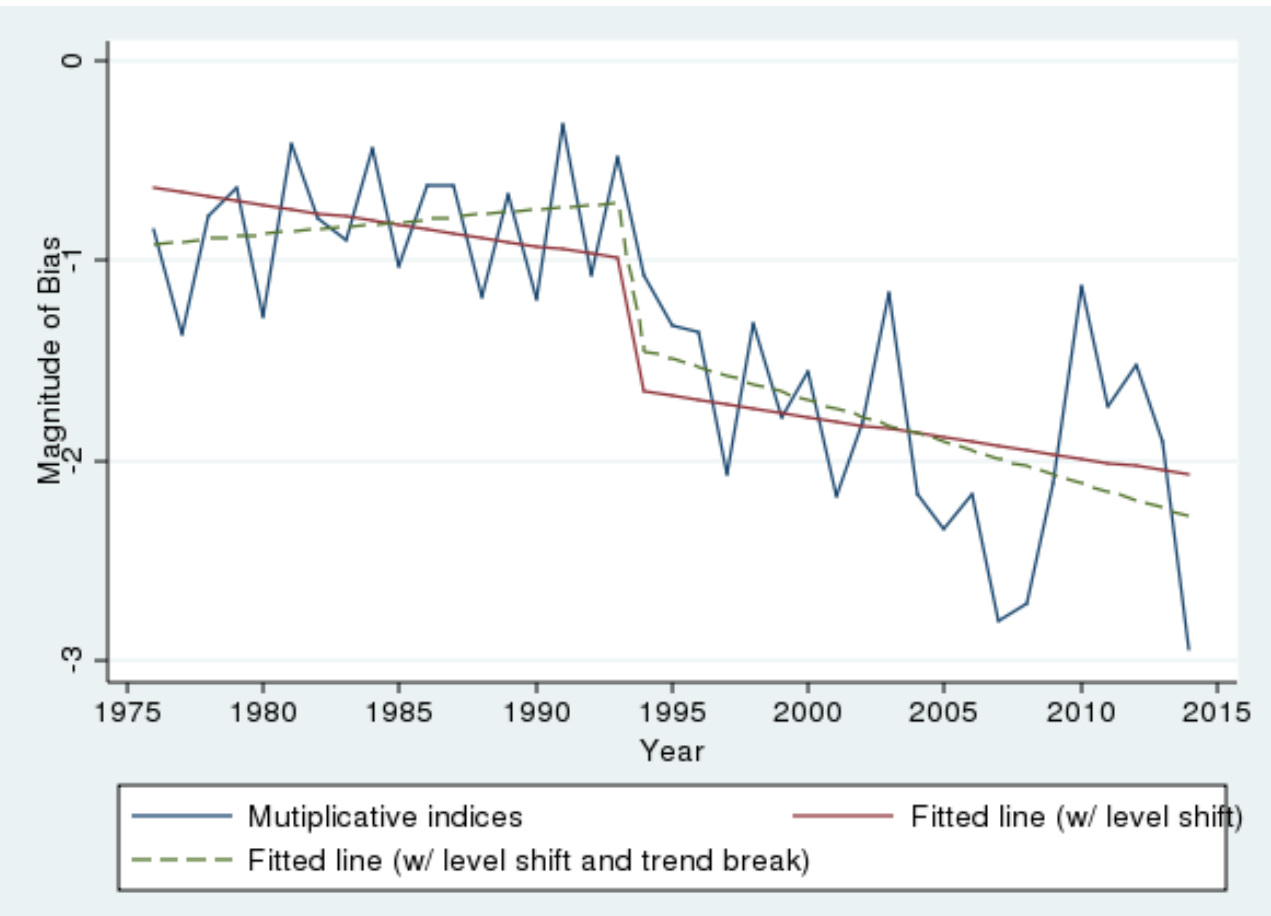

Notes: The estimates are based on the CPS monthly files from January 1976 to May 2014. The figure plots the magnitude of rotation group bias by year. The estimation of the magnitude of bias, or slope, is described in the notes of Figure 2. The solid line is the fitted line of the magnitude of bias allowing for a linear time trend and a level shift between 1993 and 1994; the dashed line is the fitted line of the magnitude of bias allowing for a linear time trend, a level shift between 1993 and 1994, and a trend break between 1993 and 1994. 


\section{The Evolution of Rotation Group Bias}

Figure 4: Rate of Type A Non-interview by Year, 1976 - May 2014.

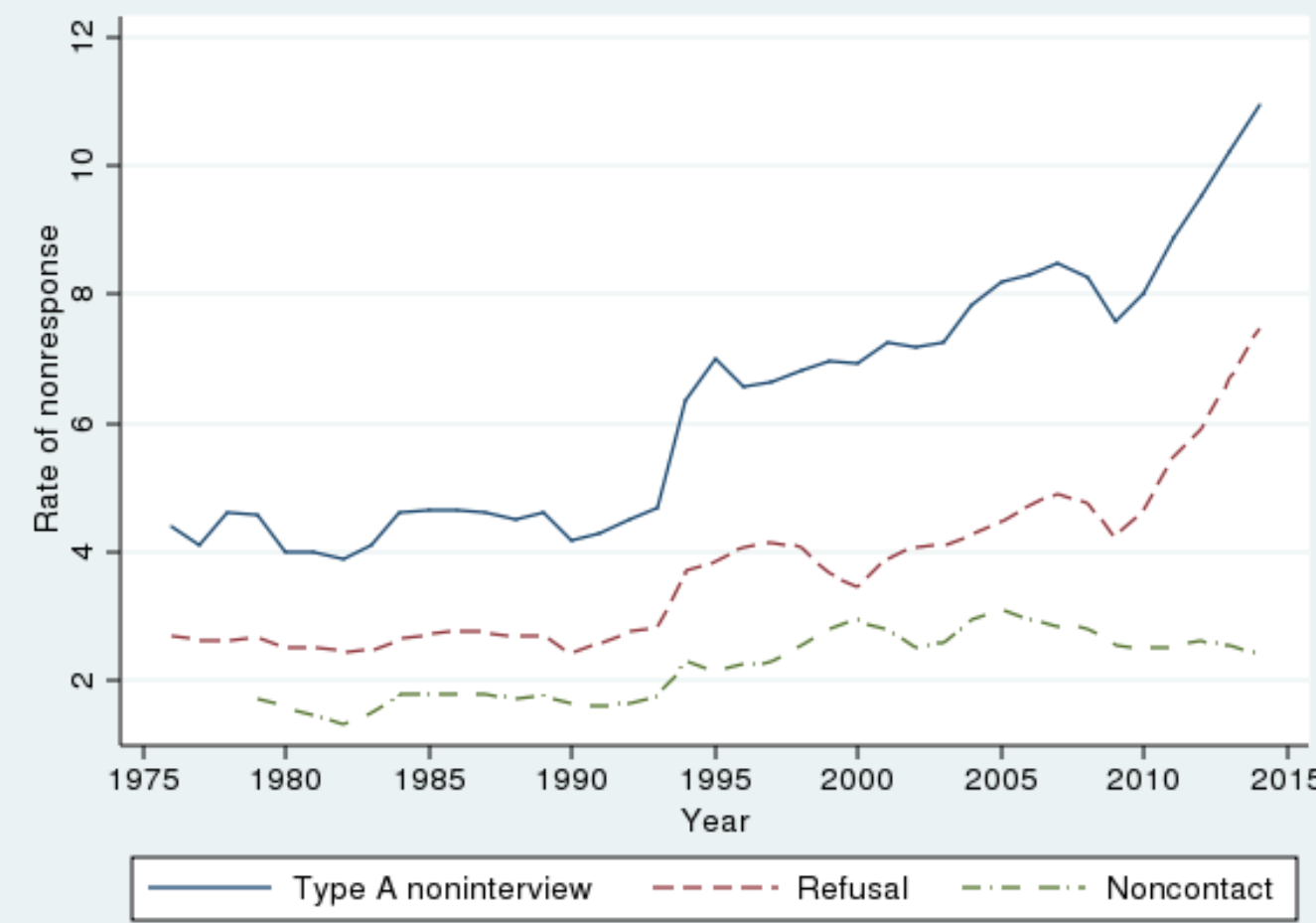

Notes: The estimates are based on the CPS monthly files from January 1976 to May 2014. The rate of type-A noninterview is the number of type-A non-interview households divided by the sum of interviewed households and type-A non-interview households. The rate of type-A non-interview due to refusal (or noncontact) is the number of type-A household for the reason of refusal (or noncontact) divided by the sum of interviewed households and type-A non-interview households. 
Figure 5: Rate of Type-A Non-interview and Magnitude of Rotation Group Bias in Unemployment Rate by Year, 1976 - May 2014.

(a) Type-A

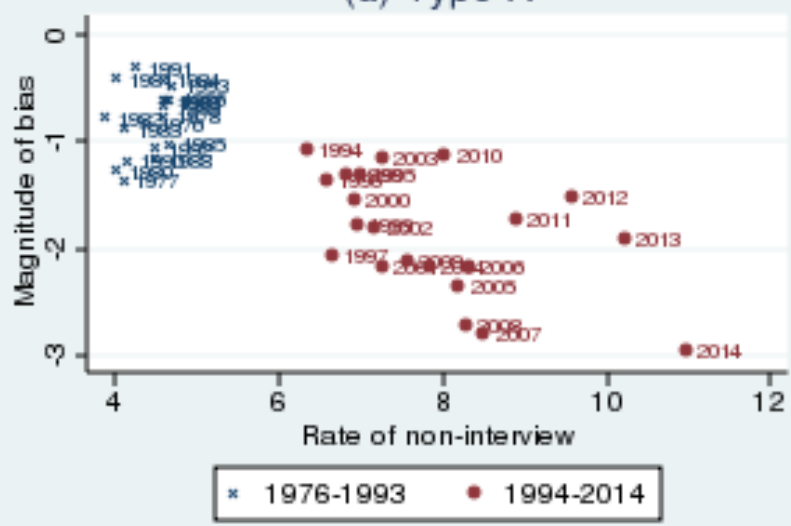

(c) Noncontact

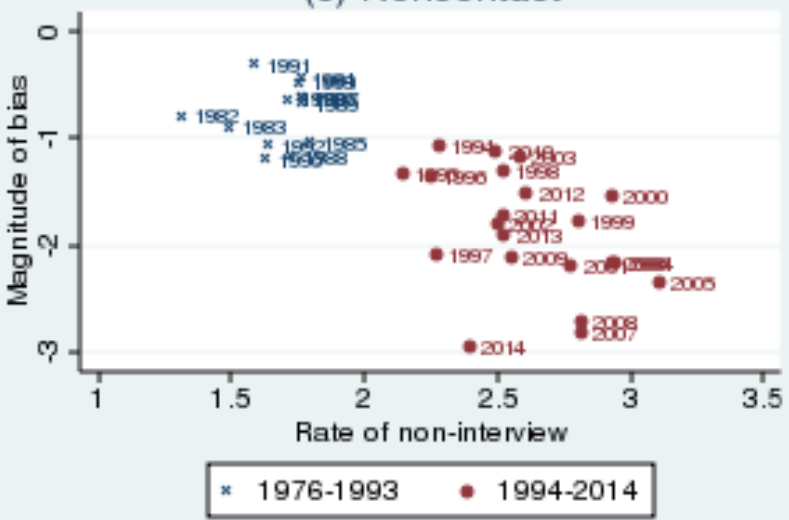

(b) Refusal

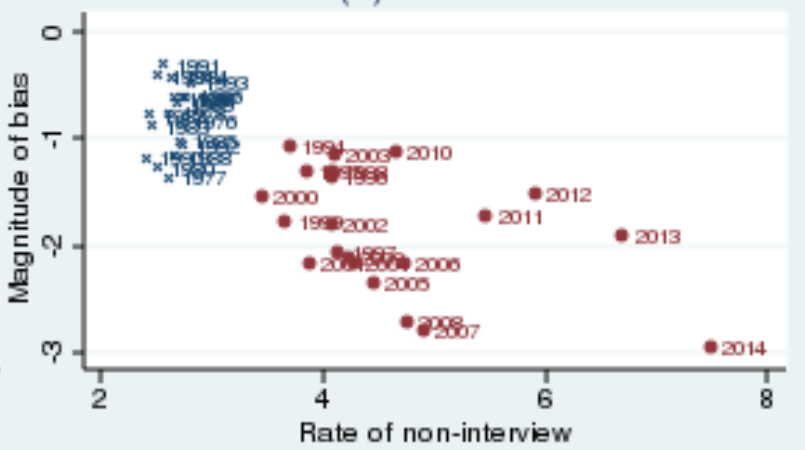

$\times \quad 1976-1993 \quad 1994-2014$

(d) Other

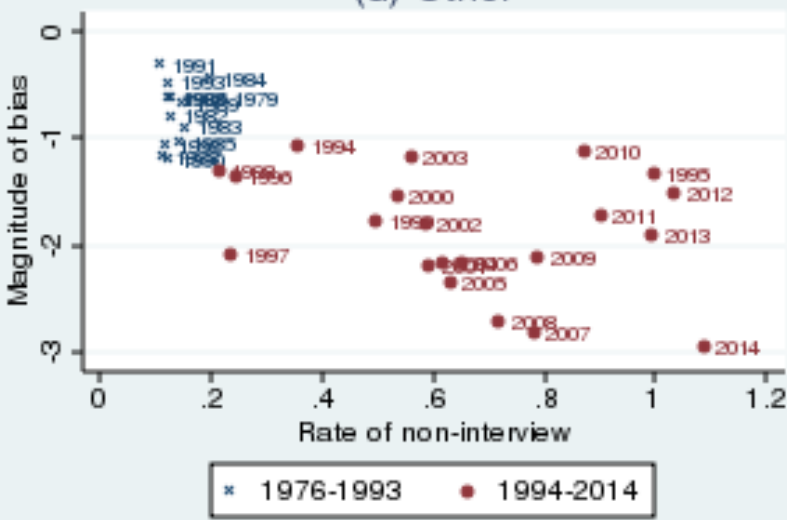

Notes: The estimates are based on the CPS monthly files from January 1976 to May 2014. The y-axis is the magnitude of rotation group bias in unemployment rate as described in the notes of Figure 2; the $\mathrm{x}$-axis is the rate of type-A non-interview. "Type A" is the number of type-A non-interview households divided by the sum of interviewed households and type-A non-interview households; "Refusal", "Noncontact", and "Type A (other)" are the fractions of households who are type-A non-interview households due to refusal, noncontact, and other reasons, respectively. 
Figure 6: Magnitude of Rotation Group Bias in the Fraction of the Labor Force Unemployed by Unemployment Duration, 1976 - May 2014.

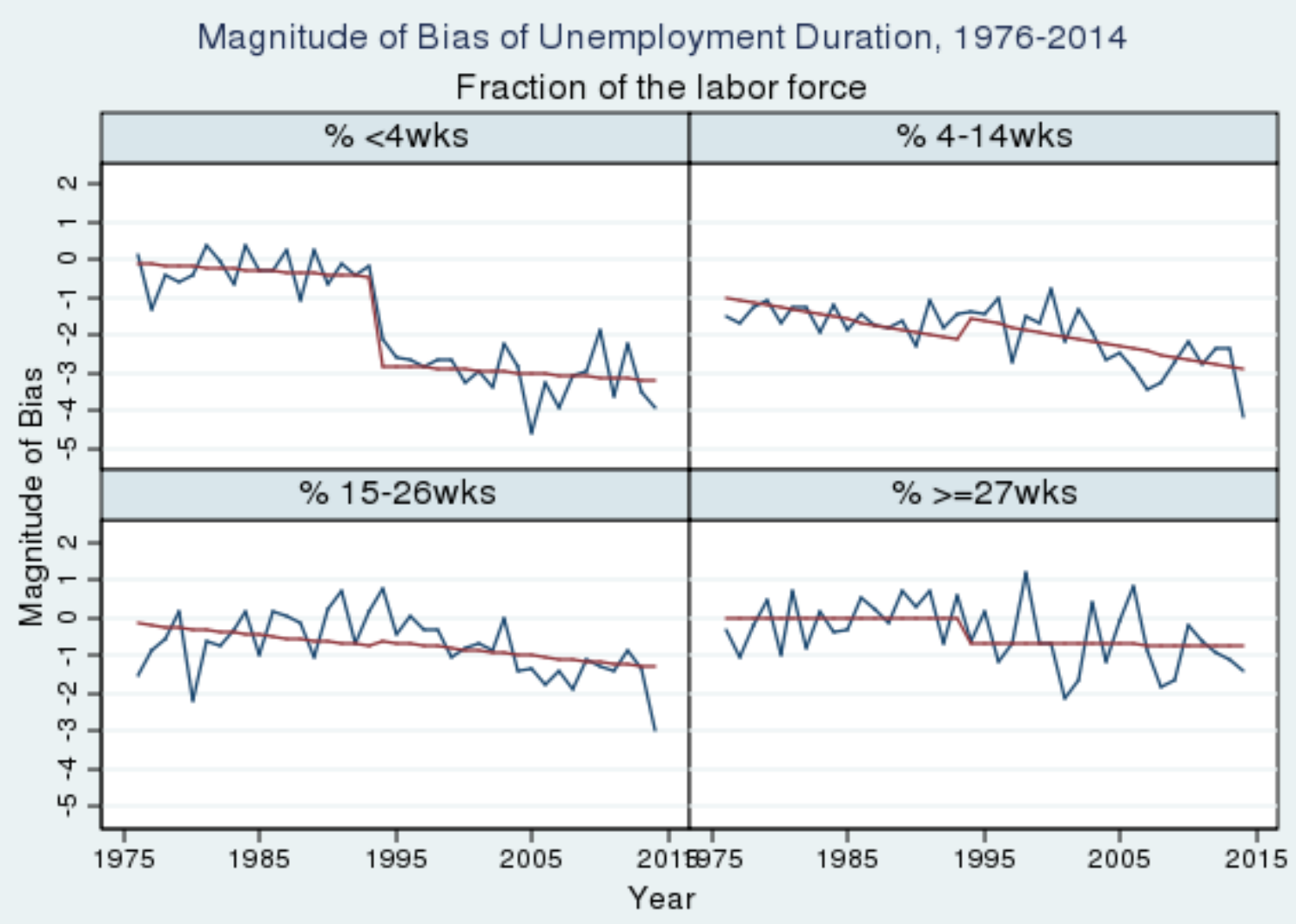

Notes: The estimates are based on the CPS monthly files from January 1976 to May 2014. The figure plots the magnitude of rotation group bias in the fraction of the labor force unemployed by unemployment duration and year. The estimation of the magnitude of bias, or slope, is described in the notes of Figure 2. The solid line is the fitted line of the magnitude of bias allowing for a linear time trend and a level shift between 1993 and 1994. 
Figure 7: Multiplicative Indices of Rotation Group Bias in Unemployment Rate by Year (U.K. LFS), 1993Q4-2013Q2.

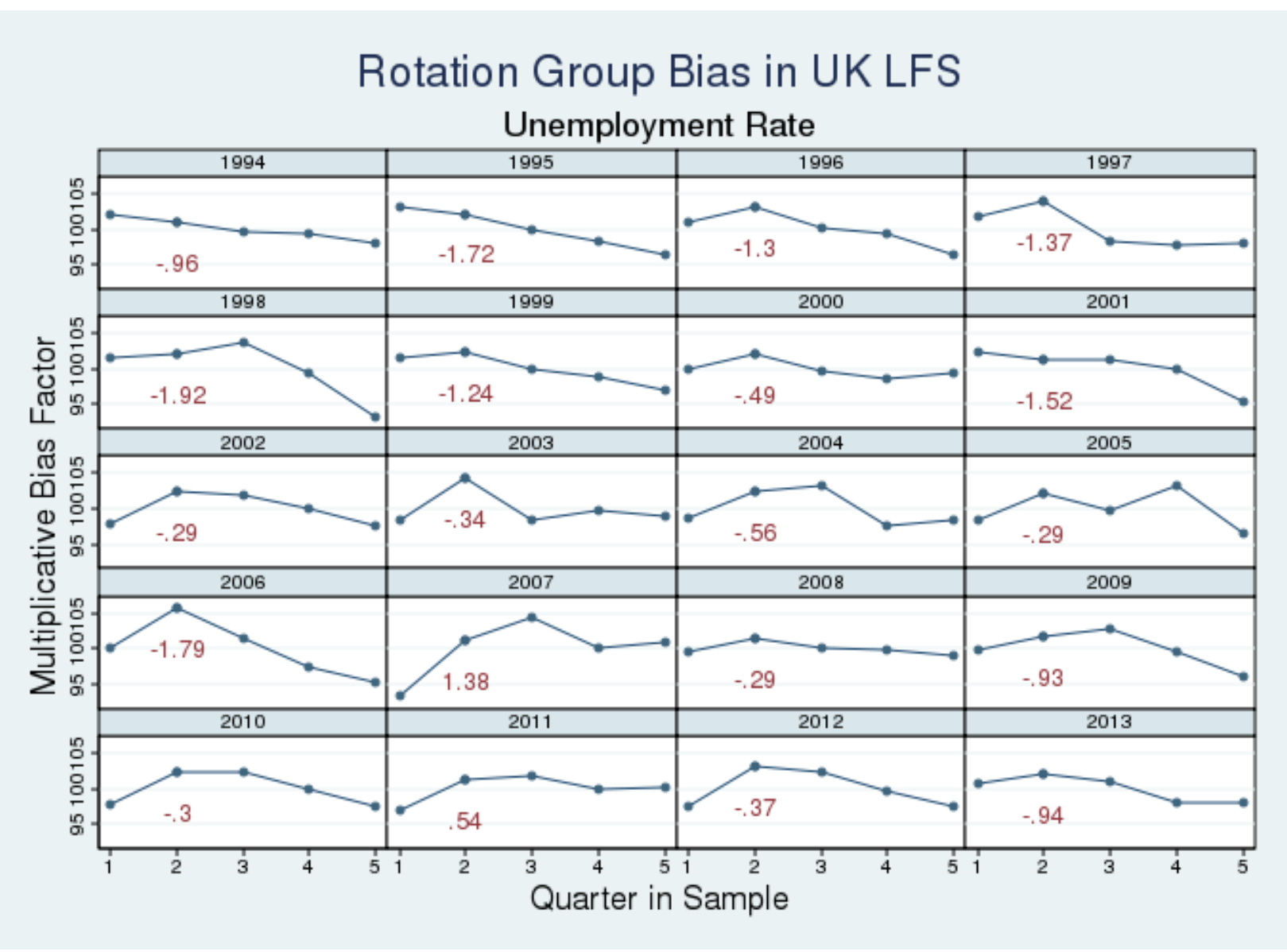

Notes: The estimates are based on the U.K. LFS from 1993Q4 to 2013Q2. The figure plots multiplicative indices of rotation group bias in unemployment rate by year. The slope of indices is given next to each figure. The estimation of multiplicative indices and slopes is described in the notes of Figure 2. 
The Evolution of Rotation Group Bias

Figure 8: Multiplicative Indices of Rotation Group Bias in Unemployment Rate by Year (Canadian LFS), 1976 - 2010.

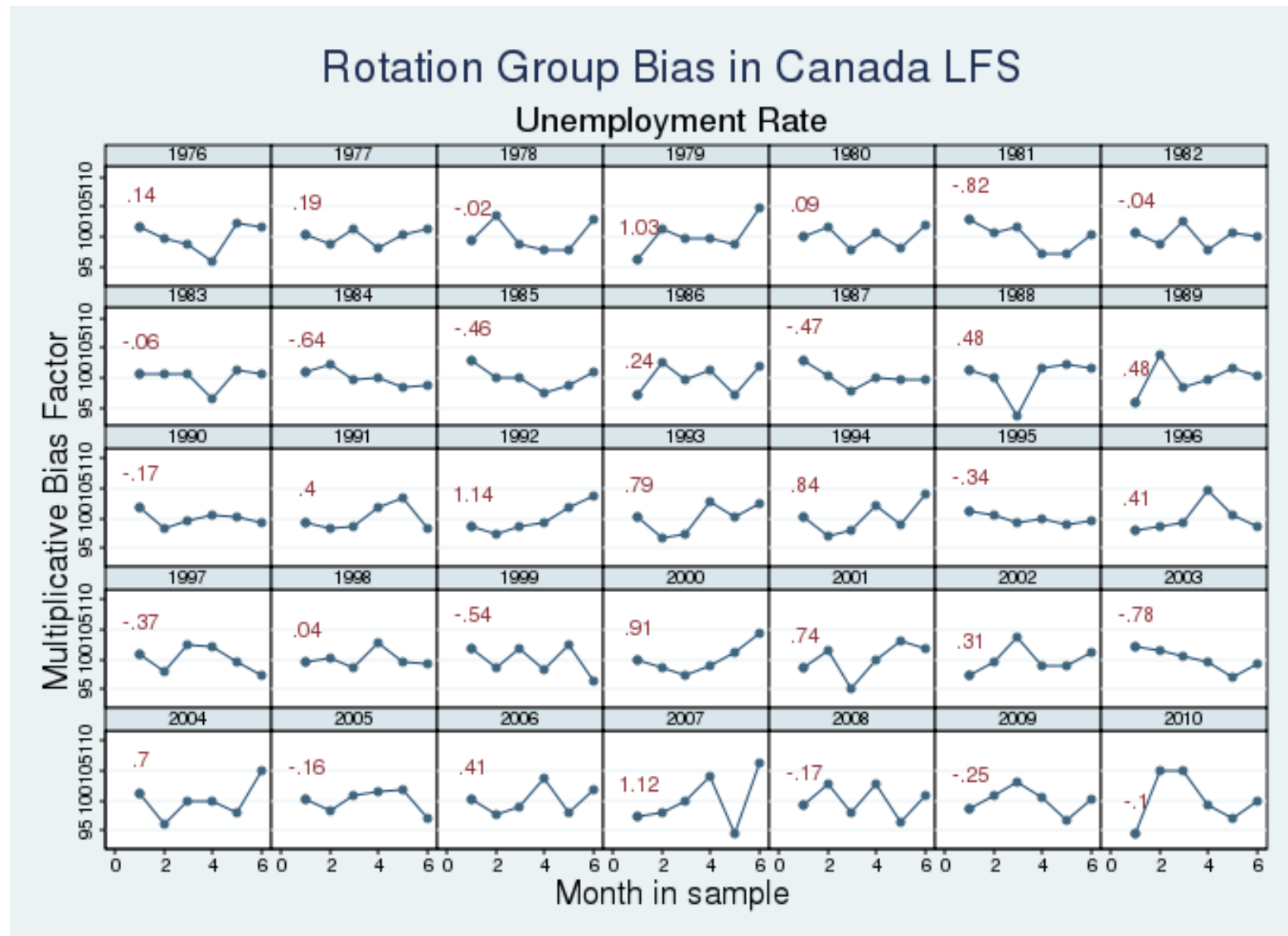

Notes: The estimates are based on the labor force statistics by rotation group and month provided by the Statistics Canada. The sample period goes from January 1976 to December 2010. The figure plots multiplicative indices of rotation group bias in unemployment rate by year. The slope of indices is given next to each figure. The estimation of multiplicative indices and slopes is described in the notes of Figure 2. 
The Evolution of Rotation Group Bias

\section{Appendix A: Additional Tables and Figures}

Table A1: Multiplicative Indices of Rotation Group Bias in Unemployment Rate with and without Imputed Labor Force Status, 1982 - August 2013.

\begin{tabular}{lcrrrrrrrr}
\hline & 1 & 2 & 3 & 4 & 5 & 6 & 7 & 8 & Mean \\
\hline with imputed values & & & & & & & & & \\
$82-93$ & 105.3 & 100.4 & 98.6 & 102.3 & 99.5 & 97.7 & 96.5 & 99.6 & $7.1 \%$ \\
$94-13$ & 108.9 & 104.0 & 100.8 & 98.9 & 100.2 & 97.0 & 95.0 & 95.2 & $6.1 \%$ \\
without imputed values & & & & & & & & \\
$82-93$ & 105.4 & 100.4 & 98.6 & 102.3 & 99.5 & 97.7 & 96.5 & 99.6 & $7.1 \%$ \\
$94-13$ & 109.2 & 104.0 & 100.7 & 98.9 & 100.2 & 97.0 & 95.0 & 95.1 & $6.1 \%$ \\
\hline
\end{tabular}

Notes: The estimates are based on the CPS monthly files from January 1982 to August 2013. The top panel presents multiplicative indices of unemployment rate with imputation for item nonresponse in labor force status; the bottom panel presents multiplicative indices without imputed labor force status. The estimation of multiplicative indices is described in the notes of Figure 2. 
Table A2: Economic Conditions and Magnitude of Rotation Group Bias in Unemployment Rate, 1976 - 2013.

\begin{tabular}{|c|c|c|c|c|c|c|c|c|}
\hline & (1) & (2) & (3) & (4) & $(5)$ & $(6)$ & $(7)$ & $(8)$ \\
\hline Time & $\begin{array}{l}-0.013 \\
(0.013)\end{array}$ & $\begin{array}{c}0.012 \\
(0.019)\end{array}$ & $\begin{array}{l}-0.007 \\
(0.014)\end{array}$ & $\begin{array}{c}0.015 \\
(0.019)\end{array}$ & $\begin{array}{l}-0.009 \\
(0.013)\end{array}$ & $\begin{array}{c}0.014 \\
(0.019)\end{array}$ & $\begin{array}{l}-0.009 \\
(0.014)\end{array}$ & $\begin{array}{c}0.014 \\
(0.020)\end{array}$ \\
\hline Post-93 & $\begin{array}{c}-0.756^{* *} \\
(0.279)\end{array}$ & $\begin{array}{c}-0.820^{* * *} \\
(0.274)\end{array}$ & $\begin{array}{c}-0.836^{* * *} \\
(0.286)\end{array}$ & $\begin{array}{c}-0.883 * * * \\
(0.281)\end{array}$ & $\begin{array}{c}-0.808^{* * *} \\
(0.279)\end{array}$ & $\begin{array}{c}-0.864 * * * \\
(0.275)\end{array}$ & $\begin{array}{c}-0.815^{* * *} \\
(0.292)\end{array}$ & $\begin{array}{c}-0.859 * * * \\
(0.286)\end{array}$ \\
\hline Time*Post-93 & & $\begin{array}{c}-0.043^{*} \\
(0.025)\end{array}$ & & $\begin{array}{l}-0.040 \\
(0.025)\end{array}$ & & $\begin{array}{l}-0.041 \\
(0.025)\end{array}$ & & $\begin{array}{l}-0.041 \\
(0.025)\end{array}$ \\
\hline Growth of Real GDP & & & $\begin{array}{c}0.044 \\
(0.038)\end{array}$ & $\begin{array}{c}0.036 \\
(0.037)\end{array}$ & & & $\begin{array}{c}0.008 \\
(0.078)\end{array}$ & $\begin{array}{l}-0.006 \\
(0.076)\end{array}$ \\
\hline Growth of Unemp Rate & & & & & $\begin{array}{l}-0.006 \\
(0.005)\end{array}$ & $\begin{array}{l}-0.005 \\
(0.004)\end{array}$ & $\begin{array}{l}-0.005 \\
(0.009)\end{array}$ & $\begin{array}{l}-0.006 \\
(0.009)\end{array}$ \\
\hline Constant & $\begin{array}{c}-0.932 * * * \\
(0.157)\end{array}$ & $\begin{array}{c}-0.695^{* * *} \\
(0.206)\end{array}$ & $\begin{array}{c}-1.019 * * * \\
(0.174)\end{array}$ & $\begin{array}{c}-0.784 * * * \\
(0.225)\end{array}$ & $\begin{array}{c}-0.902 * * * \\
(0.158)\end{array}$ & $\begin{array}{c}-0.680 * * * \\
(0.205)\end{array}$ & $\begin{array}{c}-0.923 * * * \\
(0.254)\end{array}$ & $\begin{array}{c}-0.663 * * \\
(0.295)\end{array}$ \\
\hline $\begin{array}{l}\mathrm{N} \\
\mathrm{R}^{2}\end{array}$ & $\begin{array}{c}38 \\
0.598\end{array}$ & $\begin{array}{c}38 \\
0.630\end{array}$ & $\begin{array}{c}38 \\
0.613\end{array}$ & $\begin{array}{c}38 \\
0.640\end{array}$ & $\begin{array}{c}38 \\
0.616\end{array}$ & $\begin{array}{c}38 \\
0.645\end{array}$ & $\begin{array}{c}38 \\
0.616\end{array}$ & $\begin{array}{c}38 \\
0.645\end{array}$ \\
\hline
\end{tabular}

Notes: The estimates are based on the CPS monthly files from January 1976 to December 2013. The unit of observation is calendar year. The dependent variable is the magnitude of rotation group bias in unemployment rate as described in the notes of Figure 2. "Time" is a linear time trend; "Post-93" is an indicator variable for years after 1993; "Time*Post-93" is the interaction of "Time" and "Post-93"; "Growth of Real GDP" is the annual rate of growth in real GDP; "Growth of Unemp Rate" is the annual rate of growth in unemployment rate. 
Table A3: Multiplicative Indices of Rotation Group Bias in Unemployment Rate by Interview Status (Self versus Proxy), 1976 - 2011.

(A) Weighted Counts

\begin{tabular}{rrrrrrrrrrr}
\hline & 1 & \multicolumn{1}{c}{2} & \multicolumn{1}{c}{3} & \multicolumn{1}{c}{4} & \multicolumn{1}{c}{5} & \multicolumn{1}{c}{6} & 7 & 8 & Mean & Slope \\
\hline 1976-1993 & & & & & & & & & & \\
Self & 99.9 & 100.0 & 100.1 & 100.2 & 99.8 & 99.9 & 99.9 & 100.1 & 128,264 & 0.00 \\
Proxy & 100.0 & 100.0 & 100.0 & 99.8 & 100.1 & 100.1 & 100.1 & 99.9 & 135,031 & 0.00 \\
1994-2011 & & & & & & & & & & \\
Self & 99.7 & 100.1 & 100.2 & 100.2 & 99.8 & 99.8 & 99.9 & 100.2 & 164,942 & 0.01 \\
Proxy & 100.1 & 100.4 & 100.2 & 100.0 & 100.3 & 99.7 & 99.6 & 99.6 & 163,000 & -0.10 \\
\hline
\end{tabular}

(B) Unemployment Rate

\begin{tabular}{rrrrrrrrrrr}
\hline & 1 & \multicolumn{1}{c}{2} & \multicolumn{1}{c}{3} & \multicolumn{1}{c}{4} & \multicolumn{1}{c}{5} & \multicolumn{1}{c}{6} & 7 & 8 & Mean & Slope \\
\hline 1976-1993 & & & & & & & & & & \\
Self & 108.0 & 101.0 & 99.3 & 99.7 & 101.4 & 97.7 & 96.0 & 96.9 & $7.1 \%$ & -1.26 \\
Proxy & 104.0 & 99.4 & 98.2 & 103.7 & 99.2 & 97.4 & 96.4 & 101.8 & $7.0 \%$ & -0.44 \\
1994-2011 & & & & & & & & & & \\
Self & 111.6 & 104.3 & 101.2 & 98.7 & 101.0 & 96.4 & 94.2 & 92.7 & $5.8 \%$ & -2.31 \\
Proxy & 106.7 & 103.7 & 100.2 & 99.1 & 99.7 & 97.5 & 95.7 & 97.5 & $6.0 \%$ & -1.32 \\
\hline
\end{tabular}

Notes: The estimates are based on the CPS monthly files from January 1976 to December 2011. The proxy response status is determined by matching the person line number with the line number of the household respondent. If the two line numbers do not match, the response for that person is determined to be proxy response. Panel (A) presents multiplicative indices of weighted counts by MIS and interview status; Panel (B) presents multiplicative indices of unemployment rate by MIS and interview status. The estimate of multiplicative indices is described in the notes of Figure 2. The counts are in thousands. 
Figure A1: Additive Indices of Rotation Group Bias in Unemployment Rate, 1976 - May 2014.

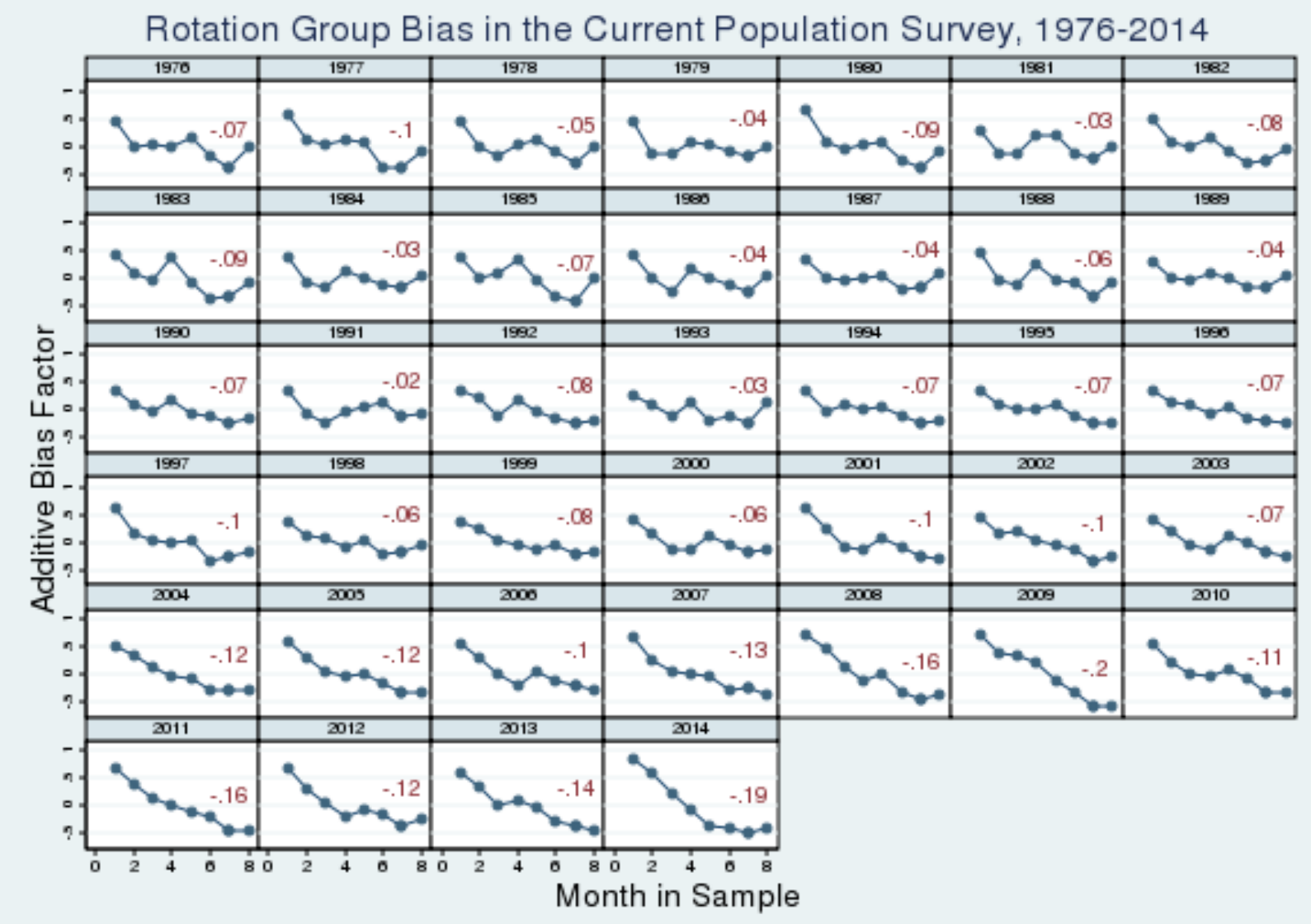

Notes: The estimates are based on the CPS monthly files from January 1976 to May 2014. The additive index is estimated by subtracting the estimate for a given rotation group by the average estimate over all eight rotation groups. 
Figure A2: Cross-sectional Relationship between the Rate of Type-A Non-interview and the Magnitude of Rotation Group Bias in Unemployment Rate by Demographic Group, 1994-2011.

(a) Type A

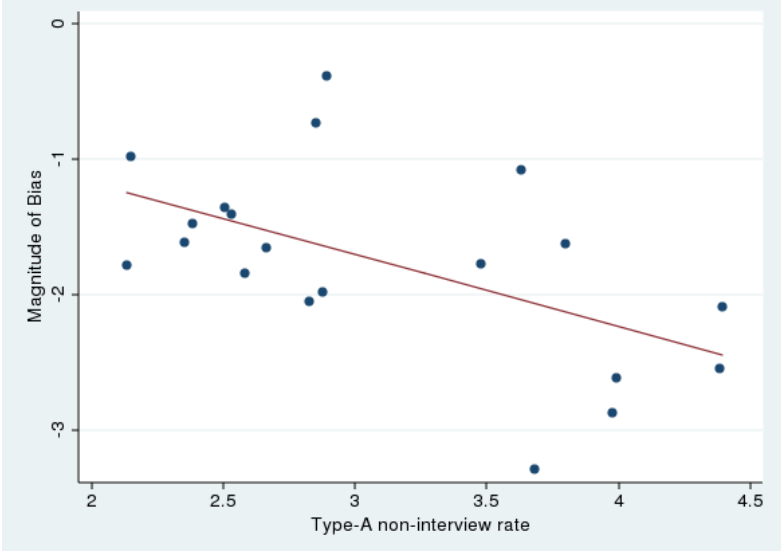

(b) Refusal

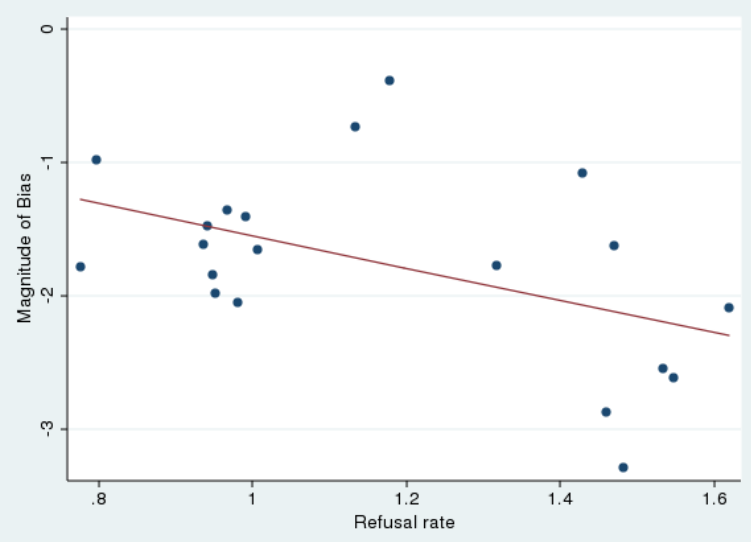

(c) Other

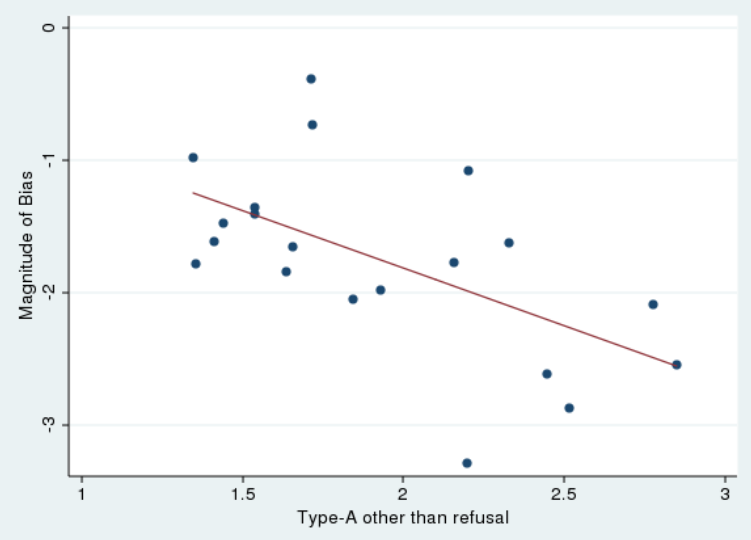

Notes: The estimates are based on the CPS monthly files from January 1994 to December 2011. The estimates correspond to those in Table 3. 
Figure A3: Magnitude of Rotation Group Bias in U1 - U6 over Time, 1976 - May 2014.

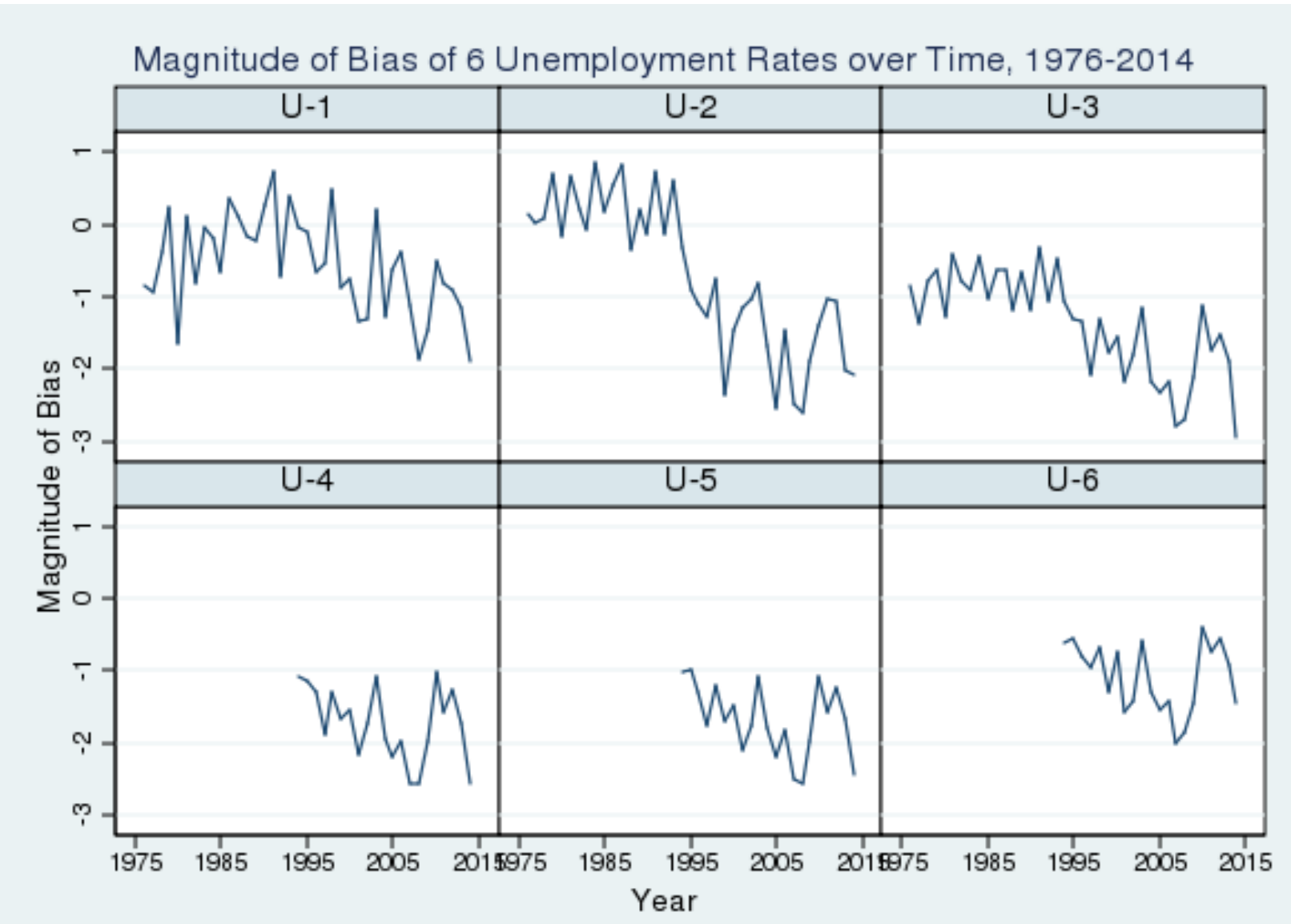

Notes: The estimates are based on the CPS monthly files from January 1976 to May 2014. The estimation of the magnitude of rotation group bias is described in the notes of Figure 2. 
Figure A4: Median Unemployment Duration and Magnitude of Rotation Group Bias in Unemployment Rate by Year, 1994-2011.

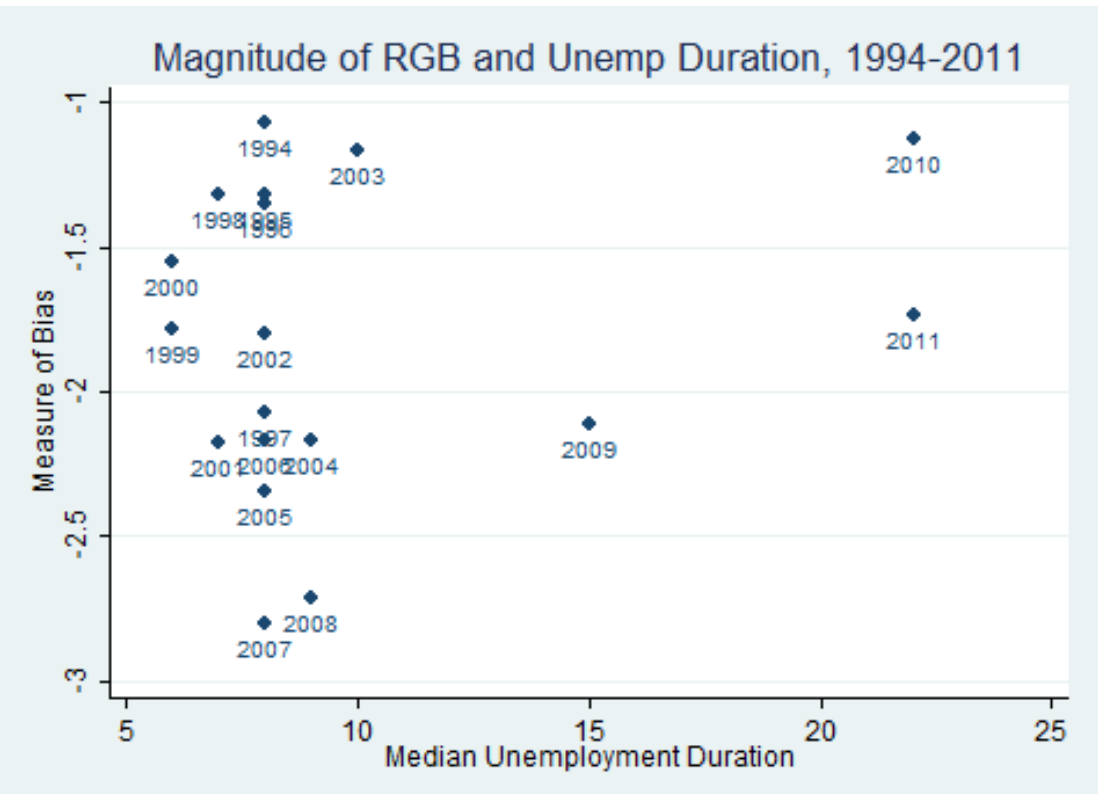

Notes: The estimates are based on the CPS monthly files from January 1994 to December 2011. The estimation of the magnitude of rotation group bias is described in the notes of Figure 2. Median unemployment duration is in weeks. 
Figure A5: Fraction of Labor Force Participants with Imputed Labor Force Status by Rotation Group (U.K. LFS), 1993Q4 - 2013Q2.

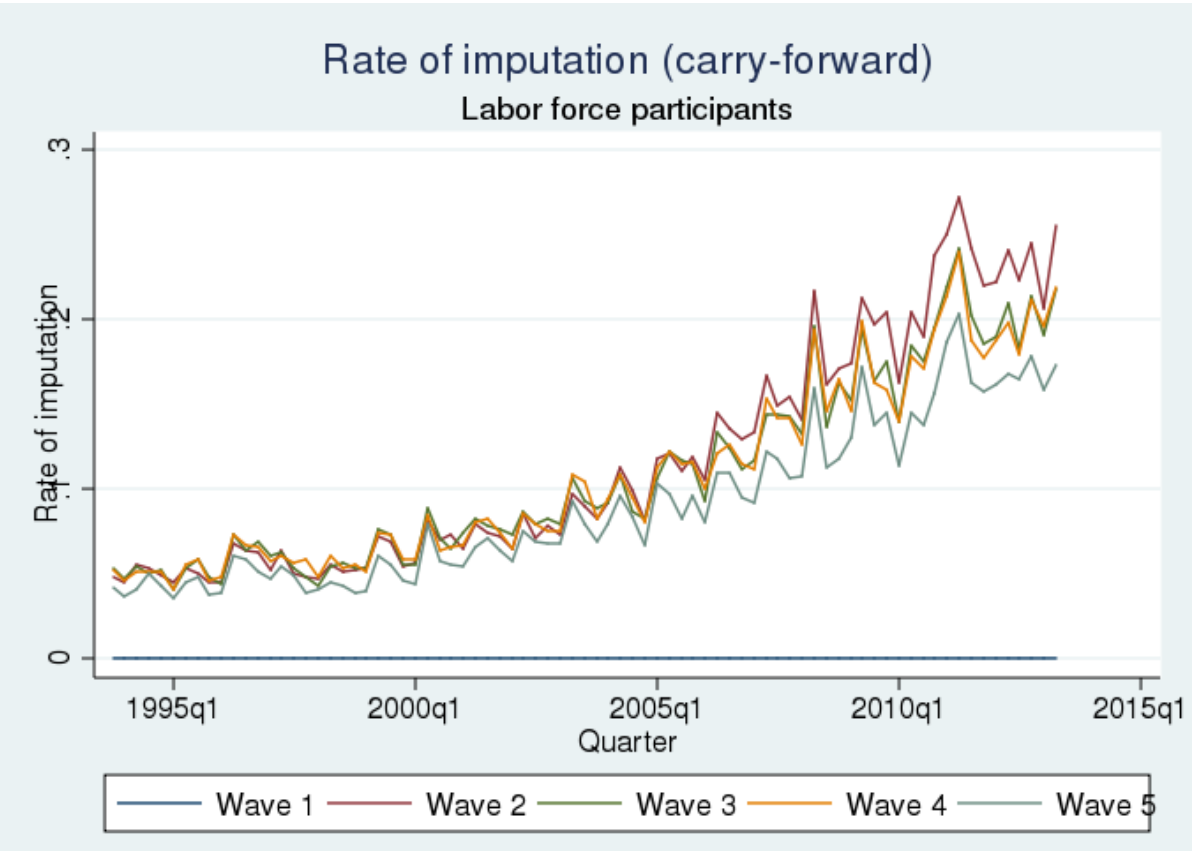

Notes: The estimates are based on the U.K. LFS from 1993Q4 to 2013Q2. The figure plots the fraction of labor force participants in the survey with imputed labor force status by rotation group. 


\section{Appendix B: Sample Construction}

\section{B.I. Construction of The CROSS-Sectional SAMPle}

The Current Population Survey (CPS) is a monthly survey of the U.S. labor force. The sampling frame of the CPS includes physical addresses. Households residing in sampled addresses are interviewed for four consecutive months, not interviewed for the next eight months, and then interviewed for an additional four months. Any given monthly survey includes eight cohorts depending on the month in which their addresses are first selected into the sample (MIS). Individuals or households who move out of sampled residences are not contacted for subsequent interviews; individuals or households who move into sampled dwellings are included in the sample for the remaining interviews. This study uses surveys from January 1976 to May 2014, unless otherwise noted. ${ }^{23}$ Sample sizes have fluctuated over time. In recent years, around 60,000 households, representing about 100,000 adults, are interviewed each month.

There are two types of nonresponses in the CPS: person/household nonresponses and item nonresponses. Among household nonresponses, only Type-A non-interview households are eligible for interview. ${ }^{24}$ BLS adjusts sample weights among interviewed households to account for nonresponses and, in principle, create a representative sample. Item nonresponses occur when an individual is interviewed but does not provide a complete set of responses. In these cases, missing responses are imputed by BLS using one of the three methods: relational, longitudinal, or hot-decking imputation. In the public-use micro-data files, imputed values for a variable are identified by a separate indicator variable.

\footnotetext{
${ }^{23}$ The surveys starting in 1994 are downloaded from the Census Bureau (available at http://thedataweb.rm.census.gov/ftp/cps ftp.html\#cpsbasic), and surveys prior to 1994 are downloaded from the National Bureau of Economic Research (available at http://www.nber.org/data/cps_basic.html).

${ }^{24}$ Two other types of non-interview, type B and type C, are not eligible for interview. A type-C unit is ineligible for interview because the address is not for occupancy. A type-B unit is intended for occupancy but is not occupied by any individual eligible for interview. A type- $\mathrm{C}$ unit is not visited again, and a type-B unit is visited in the subsequent months because the ineligibility situation is considered to be temporary.
} 
The information on labor force status used in the analysis is based on the recoded status included in the micro data. Labor force information is collected for individuals ages 16 and above. Three mutually exclusive statuses are defined: employed, unemployed, or out of labor force. We also analyze the series of questions that underlies the classification of unemployment. ${ }^{25}$ This set of questions is described in the text.

Final weights are used in our analyses. Final weights account for nonresponses, and they are adjusted to match population estimates. ${ }^{26}$ The official labor force statistics use composite weights, which put greater weights on cohorts who are present in the previous calendar month. The goal of composite weights is to increase the covariance of estimates from two consecutive calendar months, therefore reducing the sampling variance of changes. ${ }^{27}$

\section{B.2. Construction OF THE LinKed SAMPLE}

Because of the rotating panel structure, it is possible to link individuals over time. Each sampled individual could provide up to eight sets of responses.

Individuals and households are identified by unique identifiers. The identifiers have changed over time, however. Prior to 1994, three identifiers are required for linking individuals over time: household identifier, household number (identifying any change of occupying household in a dwelling), and person's line number (identifying individual within each household). Starting in 1994, additional information is required to identify a household. In

\footnotetext{
${ }^{25}$ The estimates of individual components in the definition of unemployment in the public-use micro data files might not match the official BLS definition because some instruments that the BLS uses to recode labor force status contain information that is not available in the public-use micro data files. However, the final outcome, or the number of unemployed workers, based on the series of questions from public-use micro data files is very close to the labor force status coded by the BLS.

${ }^{26}$ The matches to the population estimates are done separately for groups with different demographic characteristics, such as age, sex, race, and ethnicity.

${ }^{27}$ The BLS made composite weights available in the micro data files starting in 1998. The two sets of weights yield very similar estimates of rotation group bias.
} 
addition to the household number, two more components are combined to obtain the second part of household identifier: sample identifier and serial suffix to identify extra units.

Past survey redesigns introduced inconsistency in identifiers that prevent accurate linkage in some years. We identify cohorts with inconsistent identifiers due to changes in sampling frame. Figure B1 plots the fraction of respondents in a given rotation group who are present in all eight interviews. For our final linked sample, we exclude cohorts whose average linkage rate over eight rotation groups is far below the average. ${ }^{28}$

In addition to systematic changes in household and individual identifier, a small fraction of the identifiers are not uniquely assigned, and some assignments are not consistent over time. To deal with the non-uniqueness of identifiers, we exclude observations with duplicate household and individual identifiers within each calendar month. ${ }^{29}$ To address the issue of inconsistent identifiers over time, our sample includes individuals who report consistent demographic information in all of their interviews. Consistency in demographic information is defined as having the same reported sex, the same reported race, and reported age not varying by more than 2 years. Observations with inconsistent demographic information account for about 5 to 10 percent of the weighted population during our sample period.

\footnotetext{
${ }^{28}$ The cutoff point is approximately 40 percent. The final sample excludes cohorts who were first selected into the sample in 1976, 1977, months between April 1984 and September 1985 (inclusive), months between October 1992 and December 1993 (inclusive), and months between March 1994 and August 1995 (inclusive).

${ }^{29}$ Household and individual identifiers are uniquely assigned after 1995. Except for 1976 and 1977, the number of observations with duplicates identifiers is very low, less than 1 in 1,000 .
} 
Figure B1: Fraction of respondents presents in all eight interviews.

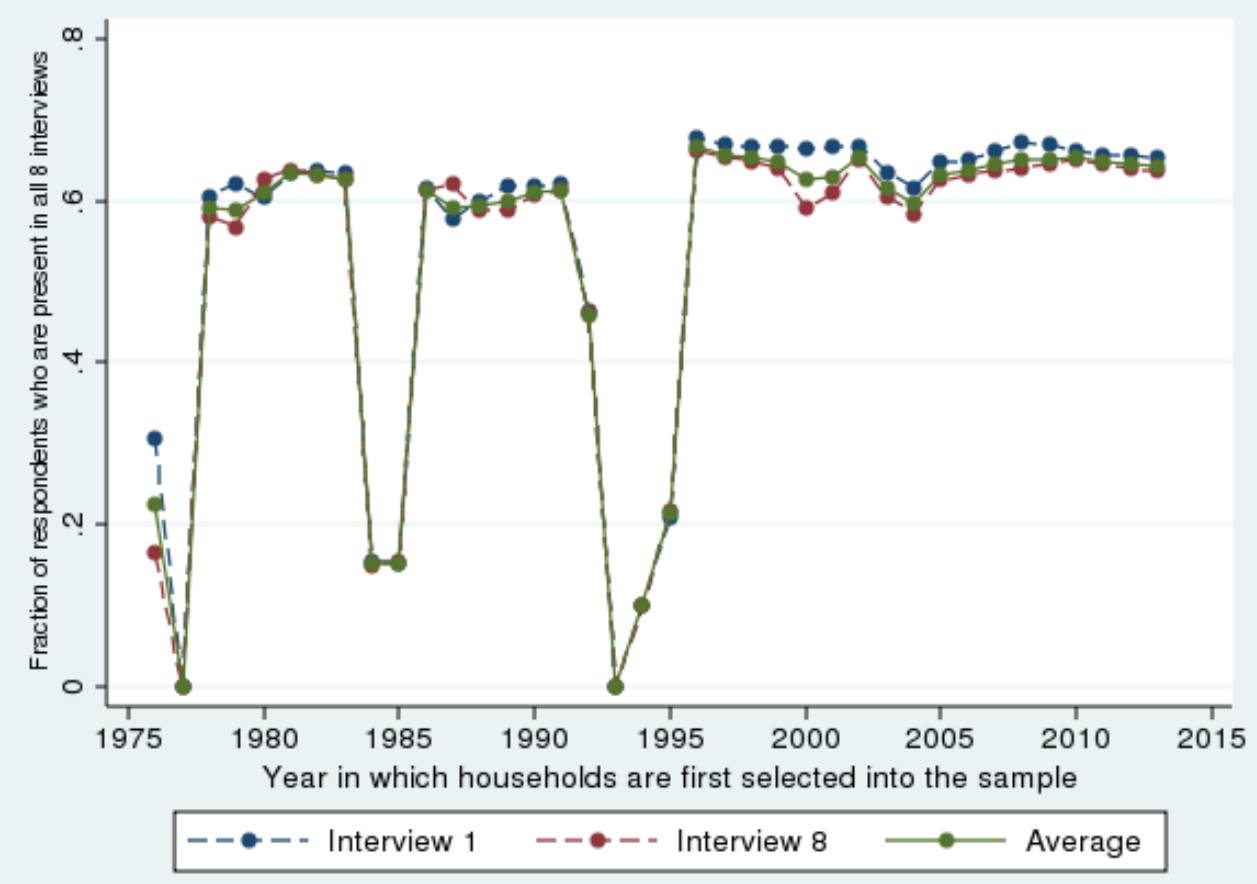

Notes: The estimates are based on the CPS monthly files from January 1976 to May 2014. The x-axis indicates interviewing cohort, or the year in which households are first selected into the sample. "Interview 1" (or "Interview 8 ") plots the fraction of respondents in the first (or eighth) rotation group who are present in all eight interviews. "Average" plots the average across all eight groups. 